\title{
Recent trends in microdialysis sampling integrated with conventional and microanalytical systems for monitoring biological events: A review
}

\author{
Pradyot Nandia,c and Susan M. Lunte ${ }^{a, b, c,{ }^{*}}$ \\ aDepartment of Pharmaceutical Chemistry, University of Kansas, Lawrence, KS 66047, United \\ States \\ bDepartment of Chemistry, University of Kansas, Lawrence, KS 66047, United States \\ 'Ralph N. Adams Institute for Bioanalytical Chemistry, University of Kansas, Lawrence, KS \\ 66047, United States
}

\begin{abstract}
Microdialysis (MD) is a sampling technique that can be employed to monitor biological events both in vivo and in vitro. When it is coupled to an analytical system, microdialysis can provide near realtime information on the time-dependent concentration changes of analytes in the extracellular space or other aqueous environments. Online systems for the analysis of microdialysis samples enable fast, selective and sensitive analysis while preserving the temporal information. Analytical methods employed for online analysis include liquid chromatography (LC), capillary (CE) and microchip electrophoresis and flow-through biosensor devices. This review article provides an overview of microdialysis sampling and online analysis systems with emphasis on in vivo analysis. Factors that affect the frequency of analysis and, hence, the temporal resolution of these systems are also discussed.
\end{abstract}

\section{Keywords}

Microdialysis; Microchip; Microfluidics; Sensors; In vivo monitoring; Electrophoresis

\section{Introduction}

There are very few tools that can be used to continuously monitor biological events with high temporal resolution. Micro-dialysis is a powerful sampling technique that makes it possible to continuously monitor the concentrations of biological molecules and other substances both in vivo and in vitro. Although the primary applications of microdialysis sampling have been in the area of neuroscience research [1], it has also been extensively employed for other pharmaceutical applications. These include the investigation of the transdermal delivery of drugs [2], tissue pharmacokinetics [3], and regional metabolism of drugs in tissues $[4,5]$.

Microdialysis probes have been placed in virtually every tissue and organ in the body including the liver [6,7], heart [8,9], skin [4,10], blood [11,12], placenta [13], stomach

(C) 2009 Published by Elsevier B.V.

*Corresponding author at: Department of Pharmaceutical Chemistry, University of Kansas, Lawrence, KS 66047, United States. Tel.: +1 785864 3320; fax: +1 785864 5736. slunte@ku.edu (S.M. Lunte). 
$[14,15]$, and ear [16]. Fig. 1 shows the microdialysis sampling process. These probes act in a manner similar to a blood vessel, allowing substances to be removed or delivered to a specific site through diffusion with no net fluid loss. The probe containing a dialysis membrane with a specific molecular weight cutoff is implanted in the physiological region of interest. It is then perfused with a fluid that is similar in ionic strength and composition to the extracellular fluid being sampled. Small molecules in the extracellular fluid that are not present in the perfusate diffuse across the membrane based on their concentration gradient and are then transported to the analysis system. Likewise, compounds in the perfusate that are not present in the extracellular fluid can be delivered directly to the physiological site of interest. Therefore, it is possible both to deliver and recover compounds from a single tissue site. This feature can be very useful for looking at site-specific release of neurotransmitters, observing regional metabolism of neuropeptides [17,18], or comparing the metabolism of antineoplastic agents in tumor vs. healthy tissue [19].

Over the past decade, a considerable amount of research has been conducted on the development of online analytical systems capable of analyzing microdialysis samples. The direct coupling of the analytical system to the microdialysis sampling system allows continuous near real-time monitoring of biological and other processes in vivo and in vitro. Online methods usually provide better temporal resolution and precision than offline analyses. This review addresses some recent advances in the development of hyphenated systems incorporating microdialysis with microanalytical systems with particular emphasis on microchip-based devices.

\subsection{Microdialysis probes}

Fig. 2 shows some typical microdialysis probe configurations. A concentric cannula design (Fig. 2A) is normally employed for neurochemical studies. These probes are composed of stainless steel and are implanted into the specific brain region of interest using a guide cannula. A typical probe used for rat brain studies is $15 \mathrm{~mm}$ long with a diameter between 200 and $500 \mu \mathrm{m}$. The dialysis membrane is located at the end of the concentric cannula and is usually from 1 to $4 \mathrm{~mm}$ in length. Probes are also available for brain sampling in mice. The mouse probes employ shorter shafts $(7-12 \mathrm{~mm})$ and have outer diameters between 220 and $380 \mu \mathrm{m}$.

For sampling soft tissue, a linear probe can be employed (Fig. 2B). These probes consist of a microdialysis membrane $(4-10 \mathrm{~mm})$ placed between two pieces of flexible tubing. Soft tissue is more homogeneous than brain tissue and, therefore, spatial resolution is not as important. Thus, the surface area of these probes is generally larger than that of the brain probe. Examples of the use of this type of probe include sampling of liver, muscle, heart and skin.

For blood sampling, a flexible probe has been developed (Fig. 2C). This type of probe was first described by Telting-Diaz et al. [20]. Its design is similar to that of the brain probe and consists of two pieces of fused silica tubing attached to the dialysis membrane. The flexible probe can bend when the animal moves, minimizing any damage to blood vessels. In general, analyte recoveries are higher from blood than from the stagnant interstitial fluid [21].

A shunt probe has also been developed for sampling from moving fluids in vivo or in vitro (Fig. 2D) [22]. This probe has been used to sample bile in awake, freely moving animals. For these experiments, the bile duct is cannulated and bile is sampled by a second dialysis membrane filled with fluid of similar ionic composition running in the opposite direction. This probe has also found use for desalting protein samples prior to introduction into a mass spectrometer [23]. 
Most microdialysis probes have molecular weight cutoffs between 20,000 and 60,000 Da. Recoveries decrease dramatically for most compounds of about 10,000 Da molecular weight. In cases of extremely fast sampling, diffusion across the dialysis membrane can be the limiting factor for temporal resolution [24]. To circumvent these problems and make it possible to sample larger molecules as well as obtain higher recoveries of small molecules, Shippy's group has developed a low-flow, push-pull perfusion device [25]. The push-pull perfusion probe consists of a $27-G$ stainless steel cannula that is perfused with saline. A fused silica capillary acts as the inner cannula and is used to withdraw fluid from the extracellular space; the fluid is then transferred to the analysis system. Flow rates using this method are from 10 to $50 \mathrm{nLmin}^{-1}$ and analyte recovery is $100 \%$.

\section{Microdialysis sampling}

Microdialysis has several advantages for sampling biological tissues and fluids, especially when combined with separation-based analytical methods. The resulting samples are most commonly composed of an aqueous salt solution that contains only small molecular weight analytes. Cells and macromolecules are excluded by the dialysis probe so centrifugation or protein precipitation steps are not required prior to analysis. In addition, because sampling is based on diffusion of substances across the dialysis membrane, no fluid is removed. Therefore, it is possible to continuously monitor substances in the extracellular fluid of the brain and other tissues for several months [26,27]. The animal can also serve as its own control. This latter advantage is particularly important for tissue distribution studies where the normal protocol is to sacrifice several animals at each time point to obtain enough data to make statistically valid conclusions.

Another significant advantage of microdialysis is that studies can be performed in awake, freely moving animals. This is especially important in studies that correlate brain drug concentration and/or neurotransmitters with behavior. Because of the small size and relatively noninvasive nature of the microdialysis probes, it is also possible to put multiple probes in a single animal. It is therefore possible to measure blood, brain, and tissue concentrations of drugs or endogenous substances simultaneously. If the animal is awake, these measurements can be correlated temporally with behavior.

A very nice example of the use of multiple probes in a single animal is shown in Fig. 3 [28]. In this experiment, the rat was given an i.v. injection of methylphenidate (Ritalin). Brain and blood sampling was accomplished using a concentric cannula probe and flexible probe, respectively. Dialysates were collected offline, and the con-centrations of methylphenidate and dopamine in both the brain and blood were determined using liquid chromatography with electrochemical detection. In this manner, it was possible to measure the transport of Ritalin across the blood-brain barrier as well as its effect on catecholamine release. Lastly, by using a "RatTurn," the extracellular concentration of these substances could be directly correlated with the overall activity level of the rat.

For long-term microdialysis studies, careful consideration should be made regarding the tissue damage associated with probe implantation. Fibrosis or gliosis can occur after several days of probe implantation [29]. Grabb et al. compared the effects of acute (2-4 h) and chronic $(24 \mathrm{~h})$ implantation of microdialysis probes. They reported the occurrence of inflammation, hemorrhage, and edema surrounding the microdialysis probe following $24 \mathrm{~h}$ of implantation; they also observed the development of fibrin-like polymer around the probe (gliosis). The extracellular edema increases the diffusional distance between the probe and the extracellular fluid, and this fibrin-like polymer can create a physical barrier between the dialysis probe and the extracellular fluid surrounding the cells [30]. Both of these factors can adversely affect recovery of the probe. In a separate study based on local cerebral blood 
flow (LCBF) and local cerebral glucose metabolism (LCGM), Benveniste et al. recommended a $24-\mathrm{h}$ period of recovery after probe implantation [31].

The integrity of the BBB following probe implantation is also a factor for discussion. Studies conducted using autoradiography with ${ }^{14} \mathrm{C}$-AIB (which does not cross the BBB under normal conditions) as well as transport characteristics of hydrophilic and moderately lipophilic drugs (following IV injection) postsurgery indicate that the BBB integrity is maintained overall $[32,33]$. However, other studies using $\mathrm{Cr}^{51}$-EDTA transport have shown a significant effect of probe implantation on BBB permeability [34].

\section{1. "Offline" vs. "online" sampling}

The analysis of microdialysis samples can be divided into two general categories, i.e., offline and online analyses, the former of which is the most common. For offline analysis, a specified volume of sample (usually 1-20 $\mu \mathrm{L}$ ) is collected in vials or tubes for later analysis. The temporal resolution that can be obtained in these experiments is usually determined by the microdialysis flow rate, analyte recovery, and the sensitivity of the analytical method. At the typical microdialysis flow rate of $1 \mu \mathrm{Lmin}^{-1}$, most offline experiments have temporal resolutions from 5 to $10 \mathrm{~min}$. An exception to this is if the analyte concentration is very high. Then smaller volume samples can be collected and diluted prior to analysis. However, in general, sample volumes of less than $1 \mu \mathrm{L}$ become very difficult to manipulate offline due to problems with surface tension and evaporation.

Online sample analysis offers several potential advantages over offline analysis. In an online system, the sample collection, manipulation, injection, and analysis steps are all integrated on a planar device in a continuous, streamlined fashion. Therefore, problems related to handling submicroliter volumes of sample (sample loss, mislabeling, evaporation, and surface tension) as well as sample degradation that can occur with sample exposure to air (e.g., ascorbic acid and catecholamines) can be avoided [35,36]. Also, such systems are usually capable of manipulating and analyzing submicroliter sample volumes, which allow high temporal resolution analysis to be performed. Such studies can yield continuous near real-time data, which provide immediate feedback on the biological process under investigation. When microdialysis sampling is directly coupled to a separation and detection method, it yields a separation-based sensor that can be used to monitor several analytes simultaneously in near real-time.

\subsection{General considerations}

When developing an online assay based on microdialysis sampling, several parameters must be taken into consideration. These parameters include:

i. Perfusion flow rate.

ii. Volume of sample available for analysis.

iii. Concentration range of analyte in the sample.

iv. Sensitivity and limit of detection of the analytical method scheme.

v. Speed of analytical method.

vi. Frequency of analysis required to draw valid conclusions (temporal resolution desired).

2.2.1. Perfusion flow rate and sample volume for analysis-Analyte recovery in microdialysis is defined by the overall mass transport of the analyte across the probe. It can be expressed as the ratio of concentration of the analyte in the dialysate to that present in the 
extracellular space or sampling solution. The amount of analyte that diffuses into the probe is a function of the concentration gradient that is produced across the dialysis membrane. This concentration gradient is established and maintained by continuously infusing the probe with fresh perfusate (e.g., aCSF in brain probes). The analytes of interest pass through the probe and is transported to the outlet end for collection or analysis. Higher recoveries (more concentrated samples) are obtained when probes are perfused at lower flow rates because this allows more time for the analyte to diffuse from the extracellular fluid across the membrane into the perfusate. Typical microdialysis perfusate flow rates are between 0.5 and $2.0 \mu \mathrm{L} \mathrm{min}-{ }^{1}$. Recoveries for small molecules are usually between $10 \%$ and $40 \%$ at these flow rates. If a flow rate of $100 \mathrm{nLmin}^{-1}$ is employed, the relative recovery approaches $100 \%$ [37]. However, use of these very low flow rates places a substantial burden on the analytical method. The method must be able to analyze submicroliter samples if one minute temporal resolution is desired as well as provide the requisite sensitivity to detect the analyte at this mass. As seen from Fig. 4, the absolute recovery (mass of substance recovered in a particular period of time) increases with higher flow rates. Therefore, with systems that require relatively large sample volumes (e.g., HPLC), it is better to sample at higher flow rates. This will lead to higher absolute recoveries as well as allow more frequent injections of sample.

The major applications of microdialysis are to measure the in vivo concentration of endogenous (neurotransmitters, peptides) or exogenous (therapeutic drugs) compounds. Therefore, analyte recovery is an important consideration in microdialysis experiments. Recovery can be described by the following equation:

$$
R=1-\exp \left(-\frac{1}{Q_{\mathrm{d}}\left(R_{\mathrm{d}}+R_{m}+R_{\mathrm{e}}\right)}\right)
$$

where $Q_{\mathrm{d}}$ is the volumetric flow rate and $R_{\mathrm{d}}, R_{\mathrm{m}}$ and $R_{\mathrm{e}}$ are the resistances of dialysate, membrane and extracellular space, respectively, to the mass transfer of analyte(s). From this equation, one can derive the factors that affect recovery. $R_{\mathrm{e}}$ includes factors such as the rate of diffusion of the analyte of interest through the extracellular space as well as metabolism and other active reactions that the analyte may undergo. $R_{\mathrm{m}}$ incorporates the probe-related factors such as probe dimension, MW cutoff, and the diffusion coefficient of the analyte across the probe membrane. $R_{\mathrm{d}}$ takes into consideration the diffusion of the analyte in the microdialysate [21,37].

It is generally assumed that $R_{\mathrm{m}} \gg R_{\mathrm{e}}$, which implies that recovery information obtained for a probe in vitro can be applied to in vivo experiments. However, the caveat attached to such an assumption is the fact that the diffusion of the analyte from distant extracellular space to the area around the probe can be slow and is dependent on the diffusion coefficient of the analyte(s) in the extracellular matrix. For large peptide neuromodulators, such sluggish diffusion can affect the recovery. In particular, peptides can also undergo metabolism and other kinetic processes in the brain before reaching the probe membrane. Other considerations include determining the effects of loss of tissue integrity due to surgery and changes in blood flow and immunological reactions following insertion of the probe.

For many in vivo applications, enough information can be obtained by monitoring the percent change of analyte with respect to the basal experiment concentration. In these experiments, the untreated animal acts as its own control. These are usually performed to demonstrate proof-of-concept rapid changes in analytes after some intervention in which the outcome is known a priori (such as a change due to the stimulation of a neurochemical pathway) [21]. During such experiments, it is generally assumed that that the probe is 
performing consistently throughout the duration of the experiment. However, careful consideration needs to be given to this assumption during the course of the experiment. For example, a tissue reaction could be triggered during perfusion that could lead to altered analyte concentrations and erroneous conclusions. Monitoring changes in endogenous compounds is an excellent application for online experiments that can make measurements with high temporal resolution on a single awake animal where the animal can serve as its own control.

Several additional factors need to be taken into consideration if more accurate in vivo concentration is warranted (such as pharmacokinetic studies). Some of those factors include the probe membrane type and its size, location of sampling probe, and flow rate. In addition, for an accurate assessment of in vivo concentration, the probe must be calibrated. There are several methods that have been reported for probe calibration with the "no-net flux" as the most popular method [38,39]. In this method, a known concentration of analyte is added to the perfusate. The concentration is usually varied over a range that is both higher and lower than the expected extracellular concentration of the exogenous or endogenous compound. The concentration of the analyte in the dialysate is measured and considered to be at the "no net flux" condition when there is no exchange of analyte between extracellular space and perfusate. This point is considered to be the extracellular fluid concentration. The major drawback of this method is the long time required to reach steady-state conditions, usually from several hours to a day. Hence, for online systems, this method of probe calibration may not be practical due to the tediousness of this process.

An easier method of probe calibration is called "retrodialysis" or "reverse dialysis" and is particularly applicable for in vivo experiments. The underlying assumption of this method is that diffusion across the probe membrane is quantitatively equal in both directions. This method uses an internal standard whose physical, biological, and pharmacokinetic properties closely resemble the compound under scrutiny. Such a compound is added at a known concentration to the perfusate, and its rate of disappearance is calculated from the equation,

$$
\text { Recovery }(\%)=100-\left(100 \times \frac{C_{\text {dialysate }}}{C_{\text {perfusate }}}\right)
$$

Calibration should ideally be done before an experiment when there is no analyte present in the tissue; this is to maintain the membrane concentration gradient during the experiment. Also, a thorough perfusion of probe with physiological solution should be performed to remove the drug delivered to the tissue during retro-dialysis [29,40]. Other in vivo recovery estimation methods include "variation of perfusion flow rate method" and "delivery method" [40].

2.2.2. Temporal resolution-Temporal resolution can be defined as the smallest increment of time over which the change in a dynamic process can be observed. For neurochemical experiments, microdialysis is usually coupled online to an instrument with the goal of analyzing samples with high temporal resolution. Many neurochemical events, such as neurotransmitter release, occur at a time scale of seconds or less. This results in very fast and transient changes in the concentration of substances in the extracellular fluid. Therefore, the primary objective in such experiments is to analyze samples as frequently as possible in order to detect these fast changes; otherwise, the concentration change could be missed due to dilution and averaging of the signal in the sample.

In the choice of an analytical method, the first question that needs to be addressed is whether the device or the method is sensitive enough to actually detect the quantity of analyte(s) 
present in the small volume of sample generated by very fast sampling. If a probe is perfused at $1 \mu \mathrm{Lmin}-{ }^{1}$ and the perfusate contains an analyte at micromolar concentrations, then the analytical system must have sufficient mass sensitivity to detect 1 pmol of analyte if 1 min temporal resolution is desired. If the analytical method is capable of detecting only 10 pmol or higher, this means that a much larger sample $(10 \mu \mathrm{L})$ must be collected in order to measure the analyte of interest. This limits the temporal resolution to $10 \mathrm{~min}$ at a flow rate of $1 \mu \mathrm{Lmin}^{-1}$.

In many cases with online systems, the temporal resolution of the technique is defined by the analysis time. If the analysis time is longer than the duration of the event being measured, then the change will appear digital and appear in the next injection. On the other hand, in those cases where the analysis step is much faster than the event being measured, it is possible to detect the change in concentration as a function of time. In this case, the rise time is defined as the time required during for the signal to increase from $10 \%$ to $90 \%$ of maximum intensity [41]. For very fast analyses, the rise time becomes dependent on the rate of diffusion of analyte across the probe membrane. However, in most cases, it is the dead volume in the system, injection method, and the flow rate of the dialysate that determine how fast a concentration change can be measured with an online system.

As mentioned in the previous section, higher analyte recovery can be achieved by using very slow flow rates. At flow rates of $100 \mathrm{nLmin}-^{1}$, analyte recoveries of $100 \%$ have been reported [37]. However, the increase in concentration of the analyte in the perfusate is offset by the extremely small sample volumes that are generated per unit time. In this case, an analytical method that is both sensitive and capable of analyzing submicroliter sample volumes is necessary if $1 \mathrm{~min}$ temporal resolution is to be obtained. This is one of the driving forces for the use of capillary and microchip electrophoresis for the analysis of microdialysis samples.

For most online separation-based microdialysis systems (described later in this review), analysis is performed on analytes such as amino acid neurotransmitters whose in vivo concentrations are relatively high and well within the detection limits of laser induced fluorescence (LIF) or other methods of detection. In such cases, the factor that dictates temporal resolution is the time that is required to separate the compounds so that serial analyses can be performed without overlapping the analysis peaks from two different runs. In other words, the difference in injection time between run 1 and run 2 should ideally be the separation time for run 1 so that as soon as run 1 ends, run 2 begins and this cycle can be repeated to get uninterrupted in vivo data. If the analysis time can be made very short (a few seconds), such a mechanism leads to high temporal resolution.

As discussed in the previous section, there are three mass transfer processes occurring in series that are associated with recovery from a microdialysis probe. The probe samples analytes that are present in the extracellular matrix surrounding the probe. However, many times the analyte needs to diffuse from the regions farther away from the probe surface to the surrounding matrix in order to be sampled. For slow diffusing analytes, the recovery will be low, indicating that one will have to wait longer to obtain enough mass to be detected. In addition, diffusion of analyte can occur within the microdialysate due to Taylor dispersion while it is being pumped to the analysis system, compromising the temporal integrity of the zones. Such phenomena can be mitigated by increasing the flow rate or reducing the length and inner diameter of the tubing.

2.2.3. Low temporal resolution studies-Online microdialysis systems can also be useful for studies where high temporal resolution is not essential. A classic example is pharmacokinetic experiments in which analysis is required every few minutes over a period 
of hours. Most drugs exhibit pharmacokinetic profiles (absorption-distribution-metabolism excretion) that last for a few hours to several days. Therefore, measuring the average concentration over a period of time (10-20 min) is sufficient for PK modeling studies.

Another application that does not require high temporal resolution but where continuous online monitoring is useful is the in vitro monitoring of products of bioreactors. Here, the time-course of the experiment is usually several hours or days. In this case, sample collection and analysis every $15 \mathrm{~min}$ can provide adequate information regarding the progress of the reaction system [42].

2.2.4. Other considerations-The development of a robust interface between microdialysis sampling and the analytical system can be challenging. Tubing and connectors associated with such an interface can produce an increase in dead volume in the system that leads to a delayed response in online monitoring experiments as well as Taylor dispersion causing band broadening. For experiments involving awake, freely moving animals, there is the additional dead volume associated with the swivel that connects the probe to the analytical system. In extreme cases, the dialysis membrane itself can be the limiting factor with regard to temporal resolution [24].

\section{Microdialysis-liquid chromatography (MD-LC)}

One of the most common separation methods used for online analysis of microdialysis samples is liquid chromatography (LC). Such a system usually consists of LC pumps, online injector with injection loop, LC column, detector, and data recorder (Fig. 5). The online injector is an integral part of online MD-LC systems as such an instrument can load and inject samples from an injection loop continuously without the requirement for autosamplers and fraction collectors. Online sampling is usually accomplished using automated valves that reduce sample loss and make it possible to perform continuous monitoring. An early report by Steele and Lunte employed multiple sample loops to continuously inject microdialysis samples without having to divert any sample to waste. In this setup, no temporal information was lost by discarding sample, and each sample represented an integrated time period depending on the time of sample collection. This system was well suited for pharmacokinetic studies [43]. Such a system can be compared to segmented flow systems discussed later where minimal or no sample is wasted.

The choice of columns for online instruments has mostly been limited to microbore and capillary columns with internal diameters ranging form 0.5 to $2 \mathrm{~mm}, 100-250 \mathrm{~mm}$ in length, and particle size $5 \mu \mathrm{m}$. The primary advantage of using microbore columns for online systems is their ability to perform small volume sample analysis at low perfusion rate through the microdialysis probe. Also, because of smaller diameter, there is less analyte dilution, resulting in improved detection limits [44].

One challenge of microbore and capillary LC separations is the need for low flow rate, pulse-free pumps as well as low dead volume and low dispersion requirements to minimize band broadening. Dead volume for microbore column systems can be reduced by minimizing the length and the internal diameter of all tubing; the flow cell for analysis also needs to have a low volume to avoid mixing and dispersion, all of which can increase band broadening. The use of microbore columns for analysis of tirazepam and its metabolites with an improved temporal resolution of 14 min compared to 23 min achieved with a conventional LC column was reported by McLaughlin et al. [19]. Online in vivo analysis of fluconazole in blood and dermis was performed by Mathy et al. These investigators reported an increase of temporal resolution from 40 to 24 min by using a microbore column [45]. Capillary liquid chromatography has also been employed with online systems employing 
mass spectrometric (MS) detection. Capillary columns are typically 50-500 $\mu \mathrm{m}$ in inner diameter and 5-200 $\mathrm{cm}$ in length. In addition to low sample volume requirements, these columns produced better ionization efficiencies resulting in improved limits of detection for MS [46].

The detection method employed for online MD-LC systems is dependent on the analyte of interest (Table 1). UV detection has been a popular detection scheme for online monitoring of drugs for pharmacokinetic studies. Electrochemical detection has been employed in a number of studies involving the detection of catecholamines and other redox active compounds of biological interest. Fluorescence detection (FL) has also been popular, but usually requires derivatization of analytes prior to analysis. One example of online MD-LCFL was reported by Yoshitake et al. in which serotonin sampled from brain was derivatized post-column with benzylamine in the presence of potassium hexaferrocyanate [47].

Mass spectrometric detection has also been employed for online MD-LC. Shackman et al. used MD-LC-MS to monitor acetylcholine in vivo with limits of detection of 8 amol [46]. In another study, the pharmacokinetics of melatonin (administered i.v. in rats) was monitored over $15 \mathrm{~h}$ using online microdialysis with LC-MS/MS [48].

There have been several applications of such online MD-LC systems over the past decade for in vivo monitoring of drugs, neurotransmitters, and other important biomolecules. Applications included primarily pharmacokinetic, metabolism, and neurochemical studies. Further information regarding the region of sampling, analyte of interest, and method of detection used for these studies can be found in Table 1.

\subsection{Comments}

The narrow diameter of capillary LC columns offers the advantage of high mass sensitivity, low flow rate requirements, and low consumption of sample and reagents that are very suitable for online microdialysate analysis [49]. However, the separation times can be relatively long, which can be detrimental for designing systems with very high temporal resolution. In addition, the robustness of cLC columns is less than that of conventional LC columns, and specialized equipment is required to load samples to such columns, which can limit its applicability [50].

\section{Microdialysis-capillary electrophoresis (MD-CE)}

Capillary electrophoresis (CE) is particularly attractive for the analysis of microdialysis samples because it has very low sample volume requirements $(\mathrm{nL}$ to $\mathrm{pL}$ ) and can perform extremely fast separations. In CE, both the analysis speed and separation efficiency improve with field strength (in the absence of Joule heating). Therefore, by using very short capillaries and high field strengths, very fast, highly efficient separations can be accomplished. When microdialysis sampling is interfaced directly to CE, it is possible to make reproducible nanoliter injections of sample into the CE capillary. The electrophoretic separations range in duration from a few minutes to several seconds. This makes it possible to continuously monitor biological processes with excellent temporal resolution.

Laser-induced fluorescence (LIF) detection is the most popular method for online MD-CE, primarily because of its high sensitivity and the availability of inexpensive lasers and laserbased detectors. There are also a large number of reagents commercially available for fluorescence derivatization of amines, thiols, carbohydrates, carboxylic acids, and other functional groups. NDA (naphthalene-2,3-dicarboxaldehyde) and OPA ( $o$-phthalaldehyde) are the most common reagents employed for the detection of amino acid neurotransmitters and other primary amines in vivo. Both of these reagents are fluorogenic and exhibit fast 
reaction kinetics, making them well suited for precolumn derivatization of amino acids prior to analysis by CE-LIF. Online reaction times for OPA/ $\beta-\mathrm{ME}$ and NDA/CN with primary amines have been reported to be 10-30 and 120-240 s, respectively [51]. Table 2 summarizes experiments performed using online MD-CE. The relevant parameters listed include the tissue region of interest, analyte measured, and detection method.

A key component of online microdialysis-CE systems is the development of an interface that is capable of injecting discrete nanoliter-size sample plugs from continuous hydrodynamic flow from the microdialysis probe $(\mu \mathrm{L})$. The first report of an online $\mathrm{MD}-\mathrm{CE}$ system by Hogan et al. used a nanoliter injection valve as the interface between the MD system and the CE separation capillary with continuously running CE separation. Perfusate from the dialysis experiment was collected in the nanoliter injection loop of the valve, and a special transfer line delivered the sample from the valve to the separation capillary inlet. The system was used to monitor antineoplastic agents in blood with a temporal resolution of $90 \mathrm{~s}$ [52]. A similar system incorporating online derivatization with NDA/CN was used for monitoring aspartate and glutamate release in the brain [53]. Later, the transdermal delivery of nicotine was monitored using an online microdialysis-capillary electrophoresis system with electrochemical detection [54]. The system incorporated a carbon fiber working electrode and a cellulose acetate decoupler before the separation capillary to shield the animal from high voltage. The cutaneous nicotine concentration was monitored for $24 \mathrm{~h}$ following application of a Nicotrol patch. The temporal resolution was $10 \mathrm{~min}$.

Lada et al. used a flow-gated interface instead of a valve to inject microdialysis samples into the separation capillary. This interface made it possible to perfuse the microdialysis probe at submicroliter per minute flow rates and still obtain temporal resolutions of 65-85 s [55]. Subsequently, the same group demonstrated extremely fast separations of glutamate and aspartate using a short capillary $(6.5 \mathrm{~cm})$ with a temporal resolution of $12 \mathrm{~s}$ [24]. A similar system was utilized to separate and perform quantitative analysis of multiple neurotransmitters in the brain (45 s temporal resolution) using micellar electrokinetic chromatography (MEKC) [56]. A system designed with a sheath-flow cuvette for improved sensitivity (15-fold) (by reducing background fluorescence and laser scattering) was reported by Bowser and Kennedy [57]. The separation capillary (10 mm ID, $150 \mathrm{~mm}$ OD) outlet was connected to a quartz cuvette (outer dimension $2 \mathrm{~mm} \times 2 \mathrm{~mm}$; inner dimension 2 $\mu \mathrm{m} \times 2 \mu \mathrm{m})$ and sheath buffer flow was maintained outside the capillary by a siphoning effect that resulted in laminar flow profile of the analytes leaving the capillary. This system was used to monitor amino acids in the brain of a freely moving animal. Seventeen amino acids were separated in $30 \mathrm{~s}$ following precolumn derivatization with NDA [51].

The most popular application of online MD-CE systems in vivo has been measuring amino acid neurotransmitters in the brain. In general, the change in concentration from basal is measured following some sort of external stimulus. In most cases, a drug or other substance is added to the perfusate to evoke the response. A common experiment is that of high potassium stimulation, which causes the release of excitatory amino acids into the extracellular fluid [53,56-59]. An electropherogram produced from such an experiment is shown in Fig. 6. The glutamate reuptake inhibitor L-trans-pyrrolidine-2,4-dicarboxylic acid (PDC) has also been administered via the microdialysis probe for monitoring glutamate and aspartate $[24,60]$. Other experiments include monitoring changes in ascorbic acid following subcutaneous injection of amphetamine [55], monitoring brain amino acids following intraperitoneal injections of saline $(0.9 \%, \mathrm{v} / \mathrm{v})$ and ethanol $(20 \%, \mathrm{v} / \mathrm{v})$ [51], and monitoring dopamine in the brain following injection of cocaine [61]. 


\subsection{Comments}

Compared to capillary LC, capillary electrophoresis can produce very fast analysis times due to application of high field strengths $(30 \mathrm{kV})$. Therefore, high temporal resolution can be attained with online systems. The major drawback of online systems using fused silica capillaries is the need for connecting tubing between the microdialysis system and the capillary electrophoresis system that can lead to band broadening and loss of temporal resolution. This is particularly the case with awake animal systems that use liquid swivels. For extremely fast separations, very short capillaries are employed at high field strengths. In humid environments, arcing can be a problem. Lastly, the online systems using conventional capillary electrophoresis are relatively large and do not lend themselves to the development of on-animal analysis systems. In contrast, the microchip systems (next section) have the potential to be completely miniaturized for use in on-animal sensing.

\section{Microdialysis-microchip electrophoresis (MD-MC)}

More recently, microchip electrophoresis has become an attractive analytical platform for the online analysis of microdialysis samples (Table 3). Microchips have several advantages for online analysis of microdialysis samples. These include the ability to manipulate samples on-chip using a combination of electroosmotic and hydrodynamic flow, integrated sample preparation or derivatization, $\mathrm{nL}$ to $\mathrm{pL}$ sample volume requirements, fast analysis times, and the ability to integrate the detector directly into the chip. Most of the research in this area has exploited one or both of the two major advantages of microchip-based devices. The first is the ability to perform very fast separations on-chip for monitoring fast biochemical processes. The second is miniaturization of the system for on-animal sensing.

Most of the work over the past several years has been focused on the development of interfaces between the microdialysis sampling system and the microchip electrophoresis system. The major challenge has been to develop an interface that can inject $\mathrm{nL}$ to $\mathrm{pL}$ volume samples continuously and reproducibly into the electrophoresis channel while still achieving adequate temporal resolution (frequency of injecting and analyzing samples) for the experiment of interest. Other challenges include interfacing the external tubing used for microdialysis sampling with the analysis chip. In addition, fast and efficient derivatization strategies must be incorporated online for detection of amino acid neurotransmitters and peptides.

Microdialysis sampling coupled to microchip electrophoresis for online analysis was first reported by Huyhn et al. [62]. The microchip device was fabricated from soda-lime glass and consisted of a twin T channel (Fig. 7A). A continuous stream of perfusate was delivered to the microchip using a syringe pump that continuously perfused the cylindrical $4 \mathrm{~mm}$ CMA/12 microdialysis probe with $20 \mathrm{mM}$ boric acid buffer. A commercially available microtight union (Upchurch Scientific) was used to connect the PEEK tubing from the microdialysis sampling system to the electrophoresis chip. Injection was accomplished using gated voltage that cut off the hydrodynamic flow at the injection cross, allowing introduction of a plug of sample into the separation channel for analysis. Such an injection scheme made it possible to continuously inject discrete plugs of microdialysis sample into the separation channel for fast electrophoretic separation of analyte. The system was used to successfully monitor the activity of the enzyme $\beta$-galactosidase. This enzyme catalyzes the hydrolysis of fluorescein mono- $\beta$-galactoside (FMG) to produce fluorescein. Both the substrate and the product were monitored using the online system with LIF detection (Fig. 7B). The lag time (time needed for the device to respond to a concentration change) on this device was 5-7 min. 
A similar setup was employed for online sampling, derivatization, and detection of an in vitro mixture of amino acids and peptides [63]. On-chip labeling of analytes was accomplished using NDA and 2-mercaptoethanol (2ME). The NDA and 2ME were dissolved in $20 \mathrm{mM}$ borate buffer and were added to the run buffer reservoir. Following a gated injection scheme, the plug of sample reacted with the derivatization reagent at the beginning of the electrophoretic separation. The analytes were separated and detected with a temporal resolution of 30-40 s.

Kennedy's group employed a gated injection scheme to continuously monitor in vivo amino acid neurotransmitters using a microdialysis microchip setup with an effective temporal resolution of 2-4 min [64]. The chip device was fabricated from borosilicate glass (Fig. 8A). Reaction channels were incorporated for the derivatization of the sample collected via a side-by-side microdialysis probe (fabricated in-house) implanted in the brain of an anesthetized rat. Precolumn reaction was achieved by mixing OPA and 2ME with the stream of microdialysate (Fig. 8B). Following reaction, a gated injection scheme introduced plugs of sample into the separation channel for analysis by LIF. The interface in this device consisted of capillary tubing from the probe outlet connected to the chip via an Upchurch fitting.

A similar approach was employed by Cellar et al. for low-flow, push-pull-based microdialysis sampling. This system also employed online derivatization followed by injection into a short fused silica CE capillary for separation and LIF detection [65]. The chip incorporated a number of valves fabricated using a multilayer soft lithography technique and actuated by nitrogen gas pressure controlled by solenoid valves. In this and the previous study, changes in concentration of the endogenous amino acid neurotransmitter (glutamate) were monitored following perfusion with high potassium. The effect of administration of the glutamate reup-take inhibitor PDC through the microdialysis probe on extracellular glutamate was also investigated.

The use of a solenoid-controlled pneumatic valving method for sample injection in an online microdialysis microchip system has been described by the Martin group [41,66]. The general design (Fig. 9) consists of one or two nitrogen-actuated PDMS microvalves that are used to inject or manipulate the flow of fluid within the chip. The CE separation channel is situated at a right angle to the flow channels. Sample injection was achieved by actuation of the valve at the flow channel/separation channel junction and was followed by electrophoresis and LIF or electrochemical detection.

In the first report, Li et al. used this approach for continuous injection and separation of fluorescein and dichlorofluorescein with temporal resolution of $20 \mathrm{~s}$ [66]. All fluids were delivered from the syringe pump or from the probe using a capillary. The lag and rise times (time needed for the response to change from 10\% to $90 \%$ of the total change) were reported to be approximately 6 and $2 \mathrm{~min}$, respectively. More recently, amperometric detection has been incorporated into the system by Mecker and Martin. In this study, the stimulated release of dopamine from PC12 cells cultured in a Petri dish was monitored using a $5 \mathrm{~mm}$ cylindrical microdialysis probe placed over the cells. In this case, the lag time was approximately $5 \mathrm{~min}$ and the rise time was $2 \min$ [41].

The use of segmented flow to create reaction chambers for derivatization has also been investigated for online microdialysis-microchip electrophoresis. Wang et al. developed a system in which aqueous sample plugs were created in a stream of oil (perfluorodecalin) [67]. The frequency and size of the droplets were dependent on the relative perfusion rates of oil and water from the respective syringe pumps (Fig. 10A). The plug of aqueous sample was interrogated at the end of a 7-cm-long capillary connected to the chip. With this system, 
glucose was measured online using glucose oxidase and Amplex Red (Fig. 10B). The same reaction scheme was employed for monitoring extracellular glucose in rat brain by microdialysis sampling; a change in glucose concentration in the brain was brought about by perfusion of $100 \mathrm{mM}$ potassium through the probe.

This interface has also been employed to perform electrophoretic separations from a continuous segmented flow, which can potentially be used for CE separation of microdialysis samples [68]. In this case, the chip consisted of a flow channel (75 $\mu \mathrm{m}$ deep and $250 \mu \mathrm{m}$ wide) and an electrophoresis channel ( $7.5 \mu \mathrm{m}$ deep and $20 \mu \mathrm{m}$ wide) that were thermally bonded with a K-shaped interface overlap for sample injection (Fig. 11A). Aqueous plugs were generated between the oil phase (perfluorodecalin) segments based on optimization studies reported previously by the Ismagilov group [69].

For injection of discrete plugs for CE separation, two modes of injection were described. For the "discrete injector," a series of sample plugs was injected; the injection volume was dependent on the electrophoresis field strength and temporal width of the plug. For the "desegmenting injector," the sample plugs coalesce at the K junction from which electrokinetic injections can be made repeatedly for analysis. Primary amines were derivatized on-chip with NDA/CN and then analyzed using the injection schemes described above. A concentration change experiment was also performed with the amino acids in which the change in concentration from $1 \mu \mathrm{M}$ to blank solution was registered on chip in 20 s (Fig. 11B). These methods offer a more reliable way to analyze sample plugs by electrophoresis while still preserving temporal information.

\subsection{Comments}

The development of online microchip-based systems is ideal for studies requiring high temporal resolution. However, there can be several challenges associated with building such devices. First, the separation must be optimized and careful consideration needs to be given to the separation and identification of the analyte(s) of interest in the matrix being sampled. Interfacing the electrophoretic separation with the hydrodynamic flow can be a long, drawnout process in which extensive investigation is required to determine the optimal microchannel design and dimensions for the specific application. For example, setting up repeated injections from a continuous flow of microdialysate can be challenging in a gated injection scheme.

Second, fabricating glass-based chips can be challenging in many lab facilities as it involves a high temperature thermal bonding step that can yield poor success rates. Glass microchips are commercially available for such applications but, for many labs, are cost prohibitive. Although PDMS microchip devices are easy to fabricate, they suffer from analyte adsorption and changing EOF. Several complex modification approaches have been suggested in the literature to reduce adsorption and maintain the EOF for a longer period of time on such devices [70]. Third, the performance of the chip is dependent on a number of factors such as removal of waste (reduce hydrostatic pressure) and frequent replenishment of buffer; integrating such steps on chip may require a fair degree of automation. Lastly, much of the equipment used for such systems must be custom built or is lab specific (e.g., software, power supplies). Therefore, a wide variety of technical resources and expertise needs to be available for developing these systems.

\section{Microdialysis coupled to biosensors}

Biosensors are analytical devices with a biological recognition element that produce an electrical signal in response to a biological change. An ideal biosensor should be able to perform continuous and reliable monitoring of analyte from complex body fluids from 
patients over a significant period of time. There are many types of biosensors. Many are enzyme-based and employ either electrochemical or optical detection. Online microdialysisbiosensor systems should be able to handle low sample volumes $(\mathrm{uL})$ if high temporal resolution is required. Also, such systems should ideally exhibit high sensitivity and specificity for the analyte(s) of interest in the presence of other endogenous electroactive analytes [71]. A flow-through biosensor has been reported for direct coupling to continuous low-flow microdialysis. Analyte selectivity for glucose and lactate was achieved in this device using immobilized oxidore-ductase enzymes followed by amperometric detection of hydrogen peroxide [72].

Online microdialysis sampling coupled to biosensors has been reported for analytes such as ascorbate [73], glucose, lactate [74,75], and glutamate [74,76,77]. The simultaneous monitoring of glucose and lactate in rats under hypoxic conditions was reported by Jones et al. [78]. Yao et al. also reported an online system for multianalyte in vivo monitoring. The biosensor consisted of a triple enzyme electrode that selectively detected glucose, L-lactate, and pyruvate without significant cross-reactivity [79]. Similar flow injection-based online systems were described by the same group for L-glutamate, acetylcholine, and dopamine [80] and $\mathrm{D}-\mathrm{L} \mathrm{L}-$ lactic acid [81].

Gramsbergen et al. developed an online system for glucose and lactate to monitor ischemic events in freely moving rats. The analytes were monitored by flow injection analysis with enzyme-based amperometric detection [82]. The development of a flow-through sensor with chemiluminescence detection for glucose monitoring in an awake rabbit has also been described [83]. Recently, online monitoring of glucose and lactate from rat brain was performed following ischemia and reperfusion. The sensor employed methylene green adsorbed on single-walled carbon nanotubes for detection [84] (Table 4).

\subsection{Comments}

Biosensors can yield good temporal resolution since no separation step is required. However, most biosensors are developed for a single analyte, so it is not possible to analyze several compounds of a similar class (catecholamines, amino acids) simultaneously as it is with separation-based sensors. Microdialysis does have an advantage over placing the sensor directly into the tissue of interest in that the probe membrane will eliminate fouling and an immune response that could be generated by sensor implantation. In addition, sensor arrays have been found to be very useful for many types of analytes and are especially valuable in the clinical setting.

\section{Concluding remarks}

Microdialysis is a well-established sampling technique that has found application in many areas, most notably in monitoring biological compounds in vivo. Advances in fabrication technologies have led to the development of innovative microchip technologies suitable for real-world monitoring applications. Microdialysis/microchip systems offer several advantages, including lower cost, faster analysis for improved temporal resolution, and simplified connections and fittings for device fabrication and operation. While the performance of conventional bench-top systems is currently superior to that of the separation-based devices, initial reports clearly demonstrate the potential of coupling microdialysis to microchip platforms.

Future developments will see the optimization of device design and the investigation of alternative materials for microchip, electrode, and membrane fabrication. It is envisioned that further advances in fabrication and integration procedures will allow the development of implantable/wearable microdialysis/microchip systems for personal or on-animal 
monitoring. Integration of the separation-based systemswith powerful detection techniques such as mass spectrometry will further improve the detection capability of these systems for biological, pharmaceutical, and environmental monitoring.

\section{Acknowledgments}

This research was supported by a research grant from the National Institutes of Health R01 (NS042929-04). Support in the form of a predoctoral fellowship from the American Heart Association for Pradyot Nandi is gratefully acknowledged. The authors would also like to thank Nancy Harmony for her assistance in the preparation of this manuscript.

\section{References}

1. Bourne JA. Intracerebral microdialysis: 30 years as a tool for the neuroscientist. Clin. Exp. Pharmacol. Physiol. 2003; 30:16-24. [PubMed: 12542448]

2. Holovics HJ, Anderson CR, Levine BS, Hui H-W, Lunte CE. Investigation of drug delivery by iontophoresis in a surgical wound utilizing microdialysis. Pharm. Res. 2008; 25:1762-1770. [PubMed: 18080730]

3. Kim A, Suecof LA, Sutherland CA, Gao L, Kuti JL, Nicolau DP. In vivo microdialysis study of the penetration of daptomycin into soft tissues in diabetic versus healthy volunteers. Antimicrob. Agents Chemother. 2008; 52:3941-3946. [PubMed: 18779352]

4. Bielecka-Grzela S, Klimowicz A. Application of cutaneous microdialysis to evaluate metronidazole and its main metabolite concentrations in the skin after a single oral dose. J. Clin. Pharm. Ther. 2003; 28:465-469. [PubMed: 14651668]

5. Lanckmans K, Clinckers R, Van Eeckhaut A, Sarre S, Smolders I, Michotte Y. Use of microbore LC-MS/MS for the quantification of oxcarbazepine and its active metabolite in rat brain microdialysis samples. J. Chromatogr. B: Anal. Technol. Biomed. Life Sci. 2006; 831:205-212.

6. Richards DA, Silva MA, Murphy N, Wigmore SJ, Mirza DF. Extracellular amino acid levels in the human liver during transplantation: a microdialysis study from donor to recipient. Amino Acids. 2007; 33:429-437. [PubMed: 17235452]

7. Davies MI, Lunte CE. Simultaneous microdialysis sampling from multiple sites in the liver for the study of phenol metabolism. Life Sci. 1996; 59:1001-1013. [PubMed: 8809214]

8. Gilinsky MA, Faibushevish AA, Lunte CE. Determination of myocardial nore-pinephrine in freely moving rats using in vivo microdialysis sampling and liquid chromatography with dual-electrod eamperometric detection. J.Pharm. Biomed. Anal. 2001; 24:929-935. [PubMed: 11248486]

9. Price KE, Vandaveer SS, Lunte CE, Larive CK. Tissue-targeted metabonomics: metabolic profiling by microdialysis sampling and microcoil NMR. J. Pharm. Biomed. Anal. 2005; 38:904-909. [PubMed: 15876508]

10. Ault JM, Riley CM, Meltzer NM, Lunte CE. Dermal microdialysis sampling in vivo. Pharm. Res. 1994; 11:1631-1639. [PubMed: 7870682]

11. Huang H, Zhang Y, Yang R, Tang X. Determination of baicalin in rat cere-brospinal fluid and blood using microdialysis coupled with ultra-performance liquid chromatography-tandem mass spectrometry. J. Chromatogr. B: Anal. Technol. Biomed. Life Sci. 2008; 874:77-83.

12. Lin L-C, Hung L-C, Tsai T-H. Determination of(-)-epigallocatechin gallate in rat blood by microdialysis coupled with liquid chromatography. J. Chromatogr. A. 2004; 1032:125-128. [PubMed: 15065787]

13. Ward KW, Pollack GM. Use of intrauterine microdialysis to investigate methanol-induced alterations in uteroplacental blood flow. Toxicol. Appl. Pharmacol. 1996; 140:203-210. [PubMed: 8887435]

14. Woo KL, Lunte CE. The direct comparison of health and ulcerated stomach tissue: a multiple probe microdialysis sampling approach. J. Pharm. Biomed. Anal. 2008; 48:85-91. [PubMed: 18620832]

15. Woo KL, Lunte CE. The development of multiple probe microdialysis sampling in the stomach. J. Pharm. Biomed. Anal. 2008; 48:20-26. [PubMed: 18539423] 
16. Zhu T, Cheung BWY, Cartier LL, Giebink GS, Sawchuk RJ. Simultaneous intravenous and intramiddle-ear dosing to determine cefditoren influx and efflux clearances in middle ear fluid in freely moving chinchillas. J. Pharm. Sci. 2003; 92:1947-1956. [PubMed: 14502535]

17. Freed AL, Cooper JD, Davies MI, Lunte SM. Investigation of the metabolism of substance P in rat striatum by microdialysis sampling and capillary electrophoresis with laser-induced fluorescence detection. J. Neurosci. Methods. 2001; 109:23-29. [PubMed: 11489296]

18. Kostel KL, Lunte SM. Evaluation of capillary electrophoresis with post-column derivatization and laser-induced fluorescence detection for the determination of substance $\mathrm{P}$ and its metabolites. $\mathrm{J}$. Chromatogr. B: Biomed. Sci. Appl. 1997; 695:27-38. [PubMed: 9271126]

19. McLaughlin KJ, Faibushevich AA, Lunte CE. Microdialysis sampling with online microbore HPLC for the determination of tirapazamine and its reduced metabolites in rats. Analyst. 2000; 125:105-110. [PubMed: 10885067]

20. Telting-Diaz M, Scott DO, Lunte CE. Intravenous microdialysis sampling in awake, freely-moving rats. Anal. Chem. 1992; 64:806-810. [PubMed: 1524225]

21. Stenken JA. Methods and issues in microdialysis calibration. Anal. Chim. Acta. 1999; 379:337357.

22. Huff JK, Heppert KE, Davies MI. The microdialysis shunt probe: profile of analytes in rats with erratic bile flow or rapid changes in analyte concentration in the bile. Curr. Sep. 1999; 18:85-90.

23. Wu Q, Liu C, Smith RD. Online microdialysis desalting for electrospray ionization-mass spectrometry of proteins and peptides. Rapid Commun. Mass Spectrom. 1996; 10:835-838.

24. Lada MW, Vickroy TW, Kennedy RT. High temporal resolutionmonitoringof glutamate and aspartate in vivo using microdialysis online with capillary electrophoresis with laser-induced fluorescence detection. Anal. Chem. 1997; 69:4560-4565. [PubMed: 9375517]

25. Kottegoda S, Shaik I, Shippy AS. Demonstration of low flow push-pull per-fusion. J. Neurosci. Methods. 2002; 121:93-101. [PubMed: 12393165]

26. Orlowska-Majdak M, Traczyk WZ, Szymanski D. Hippocampal vasopressin release evoked by Nmethyl d-aspartate (NMDA) microdialysis. Physiol. Res. 2003; 52:373-382. [PubMed: 12790771]

27. Delgado JMR, Lerma J, Martin del Rio R, Solis JM. Dialytrode technology and local profiles of amino acids in the awake cat brain. J. Neurochem. 1984; 42:1218-1228. [PubMed: 6707626]

28. Huff JK, Davies MI. Microdialysis monitoring of methylphenidate in blood and brain correlated with changes in dopamine and rat activity. J. Pharm. Biomed. Anal. 2002; 29:767-777. [PubMed: 12093508]

29. Brunner M, Derendorf H. Clinical microdialysis: current applications potential use in drug development, TrAC. Trends Anal. Chem. 2006; 25:674-680.

30. Grabb MC, Sciotti VM, Gidday JM, Cohen SA, van Wylen DG. Neurochemical and morphological responses to acutely and chronically implanted brain microdialysis probes. J. Neurosci. Methods. 1998; 82:25-34. [PubMed: 10223512]

31. Benveniste H, Drejer J, Schousboe A, Diemer NH. Regional cerebral glucose phosphorylation and blood flow after insertion of a microdialysis fiber through the dorsal hippocampus in the rat. J. Neurochem. 1987; 49:729-734. [PubMed: 3612121]

32. Benveniste H, Drejer J, Schousboe A, Diemer NH. Elevation of the extracellular concentrations of glutamate and aspartate in rat hippocampus during transient cerebral ischemia monitored by intracerebral microdialysis. J. Neurochem. 1984; 43:1369-1374. [PubMed: 6149259]

33. de Lange EC, Danhof M, de Boer AG, Breimer DD. Critical factors of intracerebral microdialysis as a technique to determine the pharmacokinetics of drugs in rat brain. Brain Res. 1994; 666:1-8. [PubMed: 7889356]

34. Major O, Shdanova T, Duffek L, Nagy Z. Continuous monitoring of blood-brain barrier opening to $\mathrm{Cr}^{51}$-EDTA by microdialysis following probe injury. Acta Neurochir. Suppl. (Wien.). 1990; 51:46-48. [PubMed: 2128582]

35. Jin G, Cheng Q, Feng J, Li F. On-line microdialysis coupled to analytical systems. J. Chrom. Sci. 2008; 46:276-287.

36. Tsai P-J, Wu J-P, Lin N-N, Kuo J-S, Yang C-S. In vivo, continuous and automatic monitoring of extracellular ascorbic acid by microdialysis and online liquid chromatography. J. Chromatogr. B: Biomed. Appl. 1996; 686:151-156. [PubMed: 8971595] 
37. Menacherry S, Hubert W, Justice JB Jr. In vivo calibration of microdialysis probes for exogenous compounds. Anal. Chem. 1992; 64:577-583. [PubMed: 1580357]

38. Justice JB Jr. Quantitative microdialysis of neurotransmitters. J. Neurosci. Methods. 1993; 48:263276. [PubMed: 8105154]

39. Lonnroth P, Jansson PA, Smith U. A microdialysis method allowing characterization of intercellular water space in humans. Am. J. Physiol. 1987; 253:E228-E231. [PubMed: 3618773]

40. Cano-Cebrian MJ, Zornoza T, Polache A, Granero L. Quantitative in vivo microdialysis in pharmacokinetic studies: some reminders. Curr. Drug Metab. 2005; 6:83-90. [PubMed: 15853760]

41. Mecker LC, Martin RS. Integration of microdialysis sampling and microchip electrophoresis with electrochemical detection. Anal. Chem. 2008; 80:9257-9264. [PubMed: 19551945]

42. Torto N, Laurell T, Gorton L, Marko-Varga G. Recent trends in the application of microdialysis in bioprocesses. Anal. Chim. Acta. 1999; 379:281-305.

43. Steele KM, Lunte CE. Microdialysis sampling coupled to on-line microbore liquid chromatography for pharmacokinetic studies. J. Pharm. Biomed. Anal. 1995; 13:149-154. [PubMed: 7766721]

44. Chaurasia CS, Chen C-E, Ashby CR. In vivo on-line HPLC-microdialysis: simultaneous detection of monoamines and their metabolites in awake freely-moving rats. J. Pharm. Biomed. Anal. 1999; 19:413-422. [PubMed: 10704106]

45. Mathy F-X, Vroman B, Ntivunwa D, De Winne AJ, Verbeeck RK, Preat V. Online determination of fluconazole in blood and dermal rat microdialysates by microbore high-performance liquid chromatography. J. Chromatogr. B: Anal. Technol. Biomed. Life Sci. 2003; 787:323-331.

46. Shackman HM, Shou M, Cellar NA, Watson CJ, Kennedy RT. Microdialysis coupled on-line to capillary liquid chromatography with tandem mass spectrometry for monitoring acetylcholine in vivo. J. Neurosci. Methods. 2007; 159:86-92. [PubMed: 16876256]

47. Yoshitake T, Iizuka R, Kehr J, Nohta H, Ishida J, Yamaguchi M. Determination of serotonin in microdialysis samples from rat brain by microbore column liquid chromatography with postcolumn derivatization and fluorescence detection. J. Neurosci. Methods. 2001; 109:91-96. [PubMed: 11513943]

48. Wong PSH, Yoshioka K, Xie F, Kissinger PT. In vivo microdialysis/liquid chromatography/ tandem mass spectrometry for the online monitoring of melatonin in rat. Rapid Commun. Mass Spectrom. 1999; 13:407-411. [PubMed: 10209876]

49. Takeuchi T. Capillary columns in liquid chromatography. Anal. Bioanal. Chem. 2003; 375:26-27. [PubMed: 12520430]

50. Schultz KN, Kennedy RT. Time-resolved microdialysis for in vivo neurochemical measurements and other applications. Annu. Rev. Anal. Chem. 2008; 1:627-661.

51. Shou M, Smith AD, Shackman JG, Peris J, Kennedy RT. In vivo monitoring of amino acids by microdialysis sampling with on-line derivatization by naphthalene-2,3-dicarboxyaldehyde and rapid micellar electrokinetic capillary chromatography. J. Neurosci. Methods. 2004; 138:189-197. [PubMed: 15325127]

52. Hogan BL, Lunte SM, Stobaugh JF, Lunte CE. Online coupling of in vivo microdialysis sampling with capillary electrophoresis. Anal. Chem. 1994; 66:596-602. [PubMed: 8154588]

53. Zhou SY, Zuo H, Stobaugh JF, Lunte CE, Lunte SM. Continuousin vivo monitoring of amino acid neurotransmitters by microdialysis sampling with online derivatization and capillary electrophoresis separation. Anal. Chem. 1995; 67:594-599. [PubMed: 7893003]

54. Zhou J, Heckert DM, Zuo H, Lunte CE, Lunte SM. Online coupling of in vivo microdialysis with capillary electrophoresis/electrochemistry. Anal. Chim. Acta. 1999; 379:307-317.

55. Lada MW, Schaller G, Carriger MH, Vickroy TW, Kennedy RT. On-line interface between microdialysis and capillary zone electrophoresis. Anal. Chim. Acta. 1995; 307:217-225.

56. Lada MW, Kennedy RT. Quantitative in vivo monitoring of primary amines in rat caudate nucleus using microdialysis coupled by a flow-gated interface to capillary electrophoresis with laserinduced fluorescence detection. Anal. Chem. 1996; 68:2790-2797. [PubMed: 8794915]

57. Bowser MT, Kennedy RT. In vivo monitoring of amine neurotransmitters using microdialysis with on-line capillary electrophoresis. Electrophoresis. 2001; 22:3668-3676. [PubMed: 11699904] 
58. Lada MW, Kennedy RT. Quantitative in vivo measurements using micro-dialysis on-line with capillary zone electrophoresis. J. Neurosci. Methods. 1995; 63:147-152. [PubMed: 8788059]

59. Lada MW, Kennedy RT. In vivo monitoring of glutathione and cysteine in rat caudate nucleus using microdialysis online with capillary zone electrophoresis-laser induced fluorescence detection. J. Neurosci. Methods. 1997; 72:153-159. [PubMed: 9133579]

60. Robert F, Bert L, Parrot S, Denoroy L, Stoppini L, Renaud B, Coupling on-line brain microdialysis. precolumn derivatization and capillary electrophoresis for routine minute sampling of O-phosphoethanolamine and excitatory amino acids. J. Chromatogr. A. 1998; 817:195-203. [PubMed: 9764494]

61. Shou M, Ferrario CR, Schultz KN, Robinson TE, Kennedy RT. Monitoring dopamine in vivo by microdialysis sampling and on-line CE-laser-induced fluorescence. Anal. Chem. 2006; 78:67176725. [PubMed: 17007489]

62. Huynh BH, Fogarty BA, Martin RS, Lunte SM. On-line coupling of micro-dialysis sampling with microchip-based capillary electrophoresis. Anal. Chem. 2004; 76:6440-6447. [PubMed: 15516139]

63. Huynh BH, Fogarty BA, Nandi P, Lunte SM. A microchip electrophoresis device with on-line microdialysis sampling and on-chip sample derivatization by naphthalene 2,3-dicarboxaldehyde/2mercaptoethanol for amino acid and peptide analysis. J. Pharm. Biomed. Anal. 2006; 42:529-534. [PubMed: 16829012]

64. Sandlin ZD, Shou M, Shackman JG, Kennedy RT. Microfluidic electrophore-sis chip coupled to microdialysis for in vivo monitoring of amino acid neurotransmitters. Anal. Chem. 2005; 77:7702-7708. [PubMed: 16316179]

65. Cellar NA, Burns ST, Meiners J-C, Chen H, Kennedy RT. Microfluidic chip for low-flow pushpull perfusion sampling in vivo with on-line analysis of amino acids. Anal. Chem. 2005; 77:70677073. [PubMed: 16255611]

66. Li MW, Huynh BH, Hulvey MK, Lunte SM, Martin RS. Design and characterization of poly(dimethylsiloxane)-based valves for interfacing continuous-flow sampling to microchip electrophoresis. Anal. Chem. 2006; 78:1042-1051. [PubMed: 16478094]

67. Wang M, Roman GT, Schultz K, Jennings C, Kennedy RT. Improved temporal resolution for in vivo microdialysis by using segmented flow. Anal. Chem. 2008; 80:5607-5615. [PubMed: 18547059]

68. Roman GT, Wang M, Shultz KN, Jennings C, Kennedy RT. Sampling and electrophoretic analysis of segmented flow streams using virtual walls in a microfluidic device. Anal. Chem. 2008; 80:8231-8238. [PubMed: 18831564]

69. Song H, Chen DL, Ismagilov RF. Reactions in droplets in microfluidic channels. Angew. Chem. Int. Ed. 2006; 45:7336-7356.

70. Miyaki K, Zeng HL, Nakagama T, Uchiyama K. Steady surface modification of polydimethylsiloxane microchannel and its application in simultaneous analysis of homocysteine and glutathione in human serum. J. Chromatogr. A. 2007; 1166:201-206. [PubMed: 17761187]

71. Zhang M, Mao L. Enzyme-based amperometric biosensors for continuous and on-line monitoring of cerebral extracellular microdialysate. Front. Biosci. 2005; 10:345-352. [PubMed: 15574373]

72. Rhemrev-Boom MM, Jonker MA, Venema K, Tiessen R, Korf J, Jobst G. Online continuous monitoring of glucose or lactate by ultraslow microdialysis combined with a flow-through nanoliter biosensor based on poly(m-phenylenediamine) ultra-thin polymer membrane as enzyme electrode. Analyst. 2001; 126:1073-1079. [PubMed: 11478638]

73. Miele M, Fillenz M. In vivo determination of extracellular brain ascorbate. J. Neurosci. Methods. 1996; 70:15-19. [PubMed: 8982976]

74. Boutelle MG, Fellows LK, Cook C. Enzyme packed bed system for the on-line measurement of glucose, glutamate, and lactate in brain microdialysate. Anal. Chem. 1992; 64:1790-1794. [PubMed: 1416036]

75. Kaptein WA, Zwaagstra JJ, Venema K, Korf J. Continuous ultraslow micro-dialysis and ultrafiltration for subcutaneous sampling as demonstrated by glucose and lactate measurements in rats. Anal. Chem. 1998; 70:4696-4700. [PubMed: 9844567] 
76. Berners MOM, Boutelle MG, Fillenz M. Online measurement of brain glutamate with an enzyme/ polymer-coated tubular electrode. Anal. Chem. 1994; 66:2017-2021. [PubMed: 7915089]

77. Miele M, Berners M, Boutelle MG, Kusakabe H, Fillenz M. The determination of the extracellular concentration of brain glutamate using quantitative microdialysis. Brain Res. 1996; 707:131-133. [PubMed: 8866723]

78. Jones DA, Ros J, Landolt H, Fillenz M, Boutelle MG. Dynamic changes in glucose and lactate in the cortex of the freely moving rat monitored using microdialysis. J. Neurochem. 2000; 75:17031708. [PubMed: 10987853]

79. Yao T, Yano T, Nishino H. Simultaneous in vivo monitoring of glucose, l-lactate, and pyruvate concentrations in rat brain by a flow-injection biosensor system with an on-line microdialysis sampling. Anal. Chim. Acta. 2004; 510:53-59.

80. Yao T, Okano G. Simultaneous determination of l-glutamate, acetylcholine and dopamine in rat brain by a flow-injection biosensor system with micro-dialysis sampling. Anal. Sci. 2008; 24:1469-1473. [PubMed: 18997377]

81. Nanjo Y, Yano T, Hayashi R, Yao T. Optically specific detection of d- and l-lactic acids by a flowinjection dual biosensor system with on-line micro-dialysis sampling. Anal. Sci. 2006; 22:11351138. [PubMed: 16896257]

82. Gramsbergen JB, Skjoth-Rasmussen J, Rasmussen C, Lambertsen KL. Online monitoring of striatum glucose and lactate in the endothelin-1 rat model of transient focal cerebral ischemia using microdialysis and flow-injection analysis with biosensors. J. Neurosci. Methods. 2004; 140:93-101. [PubMed: 15589339]

83. Li B, Zhang Z, Jin Y. Chemiluminescence flow sensor for in vivo on-line monitoring of glucose in awake rabbit by microdialysis sampling. Anal. Chim. Acta. 2001; 432:95-100.

84. Lin Y, Zhu N, Yu P, Su L, Mao L. Physiologically relevant online electrochemical method for continuous and simultaneous monitoring of striatum glucose and lactate following global cerebral ischemia/reperfusion. Anal. Chem. 2009; 81:2067-2074. [PubMed: 19281258]

85. Chang YL, Chou MH, Lin MF, Chen CF, Tsai TH. Determination and phar-macokinetic study of unbound cefepime in rat bile by liquid chromatography with on-line microdialysis. J. Chromatogr. A. 2001; 914:77-82. [PubMed: 11358234]

86. Chang YL, Chou MH, Lin MF, Chen CF, Tsai TH. Determination and phar-macokinetic study of meropenem in rat bile using on-line microdialysis and liquid chromatography. J. Chromatogr. A. 2002; 961:119-124. [PubMed: 12186382]

87. Liu SC, Tsai TH. Determination of diclofenac in rat bile and its interaction with cyclosporin A using on-line microdialysis coupled to liquid chromatography. J. Chromatogr. B: Biomed. Appl. 2002; 769:351-356.

88. Tsai TH, Cheng FC, Chen YF, Chen CF. On-line microdialysis coupled with microbore liquid chromatography with ultraviolet detection for continuous monitoring of free cefsulodin in rat blood. J. Chromatogr. A. 2001; 914:83-87. [PubMed: 11358235]

89. Tsai TH, Cheng FC, Hung LC, Chen CF. Determination of unbound ceftriaxone in rat blood by online microdialysis and microbore liquid chromatography. Int. J. Pharm. 1999; 193:21-26. [PubMed: 10581418]

90. Tsai TR, Cheng FC, Hung LC, Chen CF, Tsai TH. Determination of unbound cefmetazole in rat blood by on-line microdialysis and microbore liquid chromatography: a pharmacokinetic study. J. Chromatogr. B: Biomed. Sci. Appl. 1999; 736:129-134. [PubMed: 10676992]

91. Tsai T-H, Cheng F-C, Hung L-C, Chen C-F. Online microdialysis coupled with microbore liquid chromatography for the determination of unbound chloram-phenicol and its glucuronide in rat blood. J. Chromatogr. B: Biomed. Sci. Appl. 1998; 720:165-169. [PubMed: 9892078]

92. Tsai TH, Kao HY, Chen CF. Measurement and pharmacokinetic analysis of unbound cephaloridine in rat blood by on-line microdialysis and microbore liquid chromatography. Biomed. Chromatogr. 2001; 15:79-82. [PubMed: 11268046]

93. Yang C-S, Tsai P-J, Chen W-Y, Liu L, Kuo J-S. Determination of extracellular glutathione in livers of anesthetized rats by microdialysis with online high-performance liquid chromatography. J. Chromatogr. B: Biomed. Appl. 1995; 667:41-48. [PubMed: 7663684] 
94. Portas CM, Bjorvatn B, Fagerland S, Gronli J, Mundal V, Sorensen E, Ursin R. Online detection of extracellular levels of serotonin in dorsal raphe nucleus and frontal cortex over the sleep/wake cycle in the freely moving rat. Neuroscience. 1998; 83:807-814. [PubMed: 9483564]

95. -C Cheng F, Tsai T-H, Wu Y-S, Kuo J-S, Chen CF. Pharmacokinetic and pharmacodynamic analyses of trazodone in rat striatum by in vivo microdialysis. J. Pharm. Biomed. Anal. 1999; 19:293-300. [PubMed: 10704094]

96. Tsai TH, Hung LC, Chang YL, Shum AYC, Chen CF. Simultaneous blood and brain sampling of cephalexin in the rat by microdialysis and microbore liquid chromatography: application to pharmacokinetics studies. J. Chromatogr. B: Biomed. Sci. Appl. 2000; 740:203-209. [PubMed: 10821406]

97. Leggas M, Zhuang Y, Welden J, Self Z, Waters CM, Stewart CF. Microbore HPLC method with online microdialysis for measurement of topotecan lactone and carboxylate in murine CSF. J. Pharm. Sci. 2004; 93:2284-2295. [PubMed: 15295789]

98. Tseng W-C, Yang M-H, Chen T-P, Huang Y-L. Automated, continuous, and dynamic speciation of urinary arsenic in the bladder of living organisms using microdialysis sampling coupled on-line with high performance liquid chromatography and hydride generation atomic absorption spectrometry. Analyst. 2002; 127:560-564. [PubMed: 12022658]

99. Wang Q, Yang H, Miller DW, Elmquist WF. Effect of the P-glycoprotein inhibitor, cyclosporin A, on the distribution of rhodamine-123 to the brain: an in vivo microdialysis study in freely moving rats. Biochem. Biophys. Res. Commun. 1995; 211:719-726. [PubMed: 7598699]

100. Tsai TH, Tsai TR, Chen YF, Chou CJ, Chen CF. Determination of unbound 20(S)-camptothecin in rat bile by on-line microdialysis coupled to microbore liquid chromatography with fluorescence detection. J. Chromatogr. B: Biomed. Sci. Appl. 1999; 732:221-225. [PubMed: 10517239]

101. Malhotra BK, Lemaire M, Brouillard JF, Sawchuk RJ. High-performance liquid chromatographic analysis of (S)-[alpha]-amino-5-phosphonomethyl[1,1'-biphenyl]-3-propanoic acid (EAB 515) in brain and blood microdialysate (on-line) and in plasma ultrafiltrate of freely moving rats. J. Chromatogr. B: Biomed. Appl. 1996; 679:167-176. [PubMed: 8998557]

102. Yang CS, Tsai PJ, Chen WY, Kuo JS. On-line, continuous and automatic monitoring of extracellular malondialdehyde concentration in anesthetized rat brain cortex. J. Chromatogr. B: Biomed. Sci. Appl. 2001; 752:33-38. [PubMed: 11254194]

103. O’Brien KB, Bowser MT. Measuring D-serine efflux from mouse cortical brain slices using online microdialysis-capillary electrophoresis. Electrophoresis. 2006; 27:1949-1956. [PubMed: 16703626]

104. Ciriacks CM, Bowser MT. Measuring the effect of glutamate receptor agonists on extracellular dserine concentrations in the rat striatum using online microdialysis-capillary electrophoresis. Neurosci. Lett. 2006; 393:200-205. [PubMed: 16266784]

105. O’Brien KB, Esguerra M, Miller RF, Bowser MT. Monitoring neurotransmitter release from isolated retinas using online microdialysis-capillary electrophoresis. Anal. Chem. 2004; 76:50695074. [PubMed: 15373444]

106. O’Brien KB, Esguerra M, Klug CT, Miller RF, Bowser MT. A high-throughput on-line microdialysis-capillary assay for d-serine. Electrophoresis. 2003; 24:1227-1235. [PubMed: 12707916]

107. Plock N, Kloft C. Microdialysis-theoretical background and recent implementation in applied life-sciences. Eur. J. Pharm. Sci. 2005; 25:1-24. [PubMed: 15854796] 
(A)
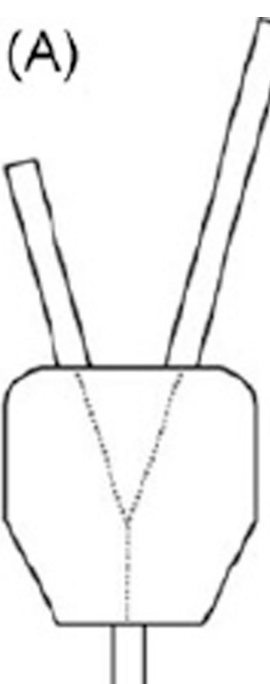

(B)

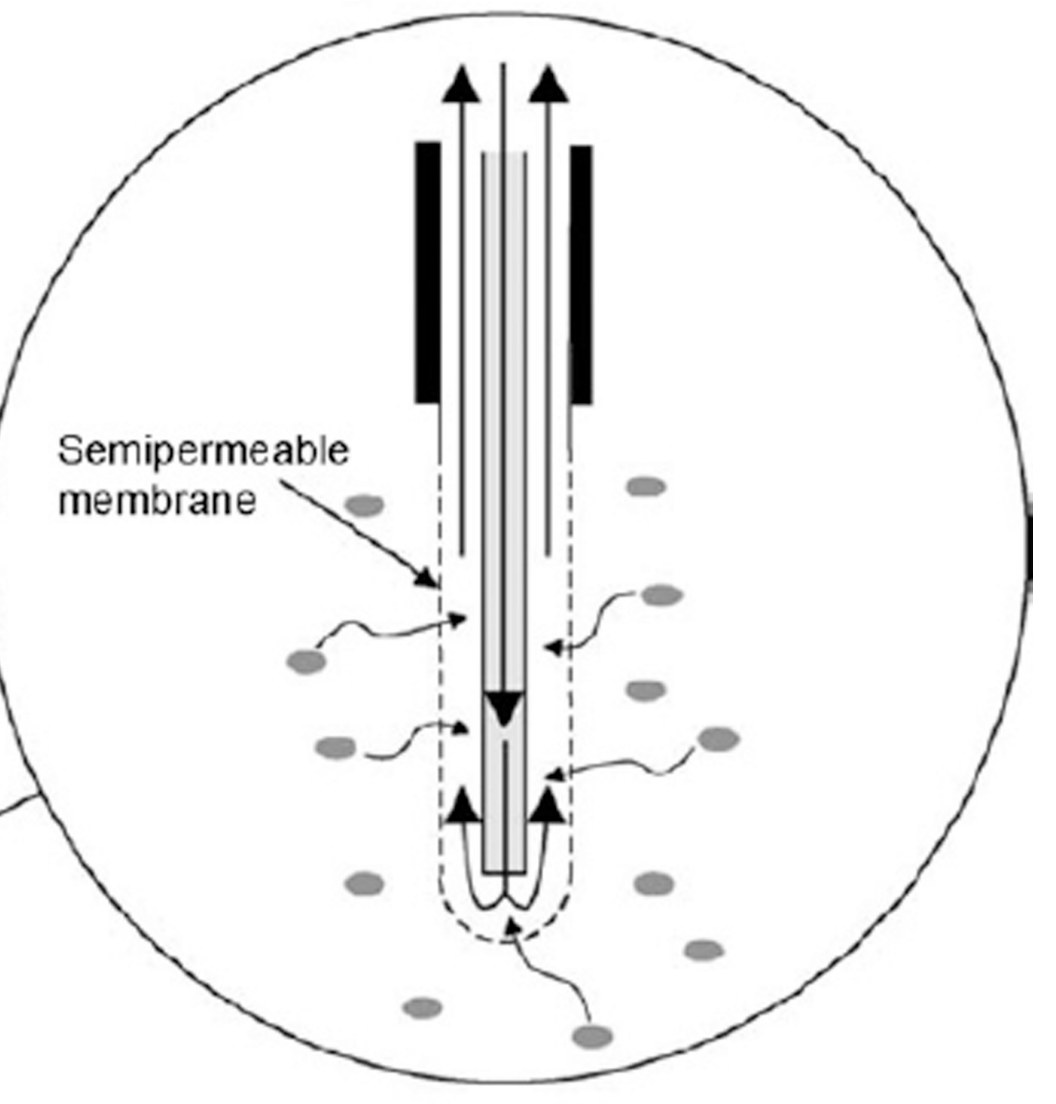

Fig. 1.

Sampling process across microdialysis probe membrane (from Plock and Kloft, [107]). 
(A)

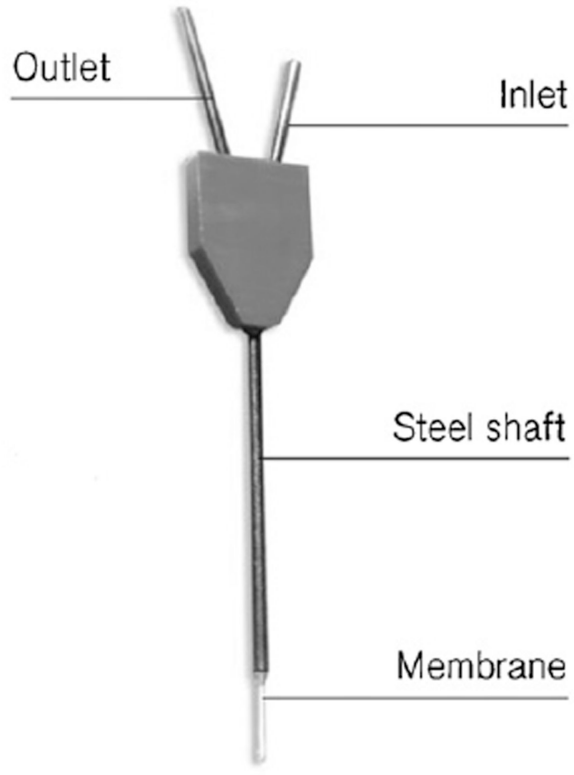

(B)

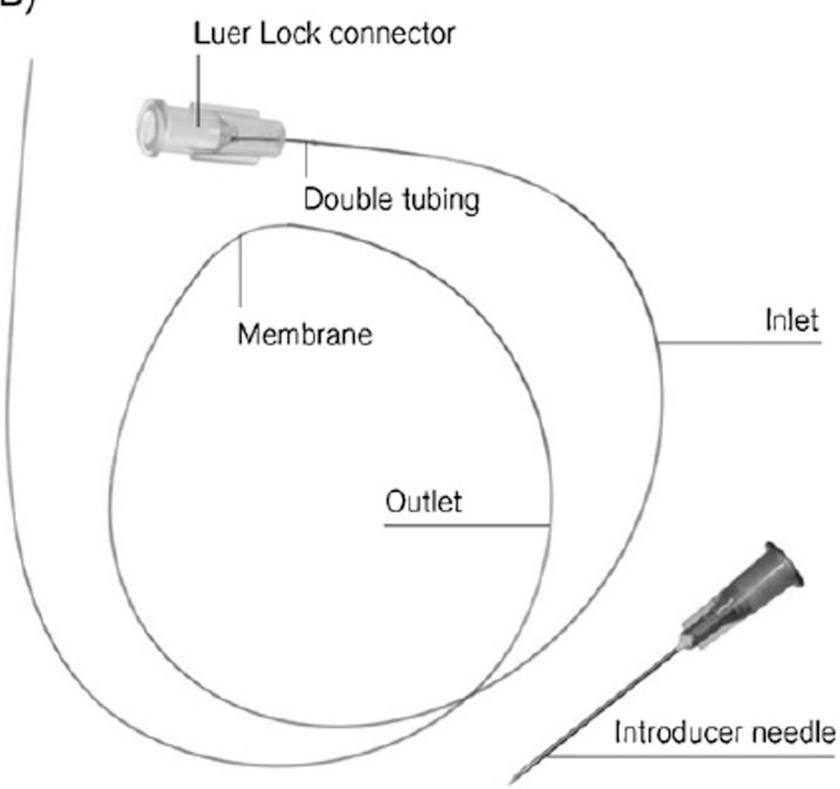

(C)

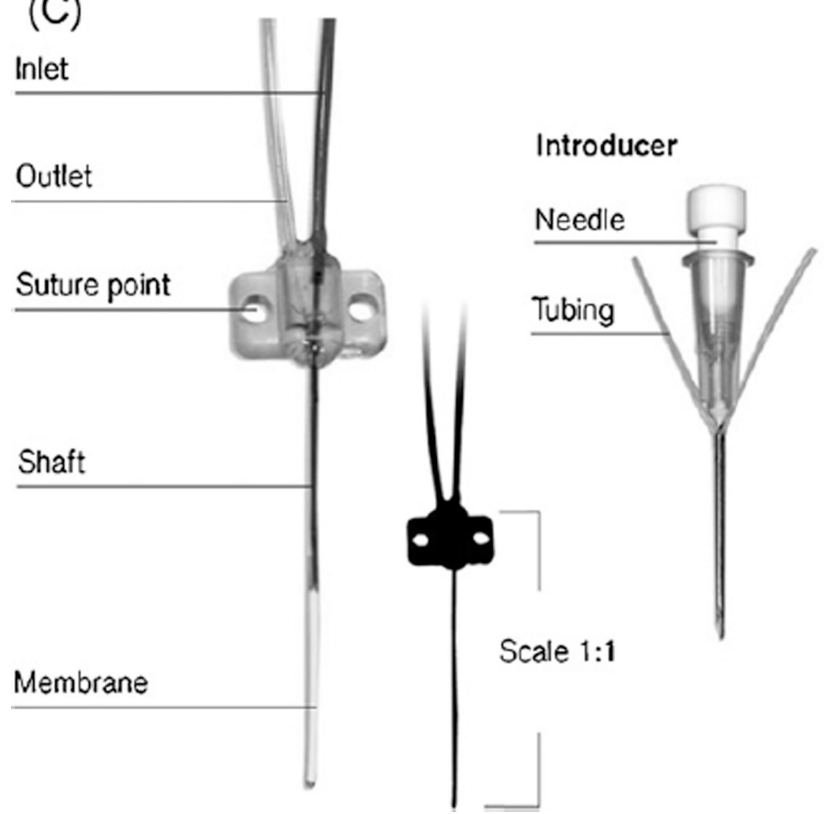

(D)

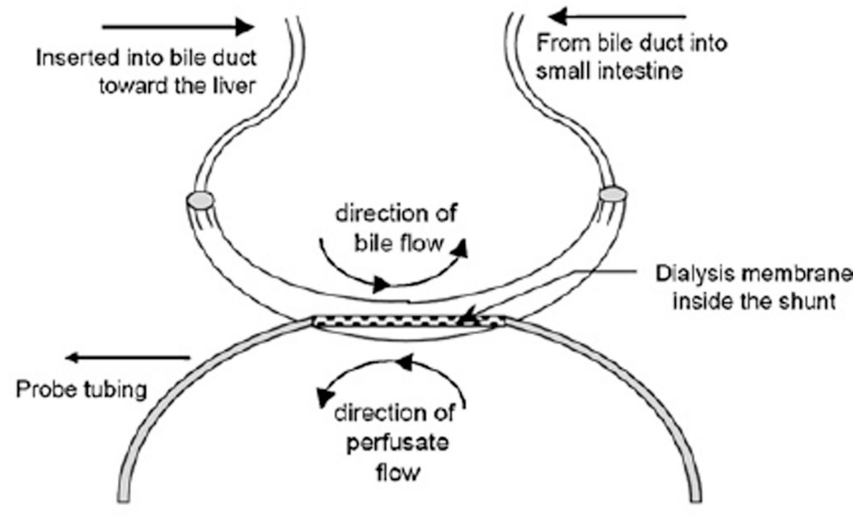

Fig. 2.

Microdialysis probes. (A) Cylindrical probe for brain. (B) Linear probe for peripheral tissues. (C) Flexible probe for intravenous use. (D) Shunt probe for bile duct sampling ((AC) CMA product catalogue; (D) Huff et al. [22]). 


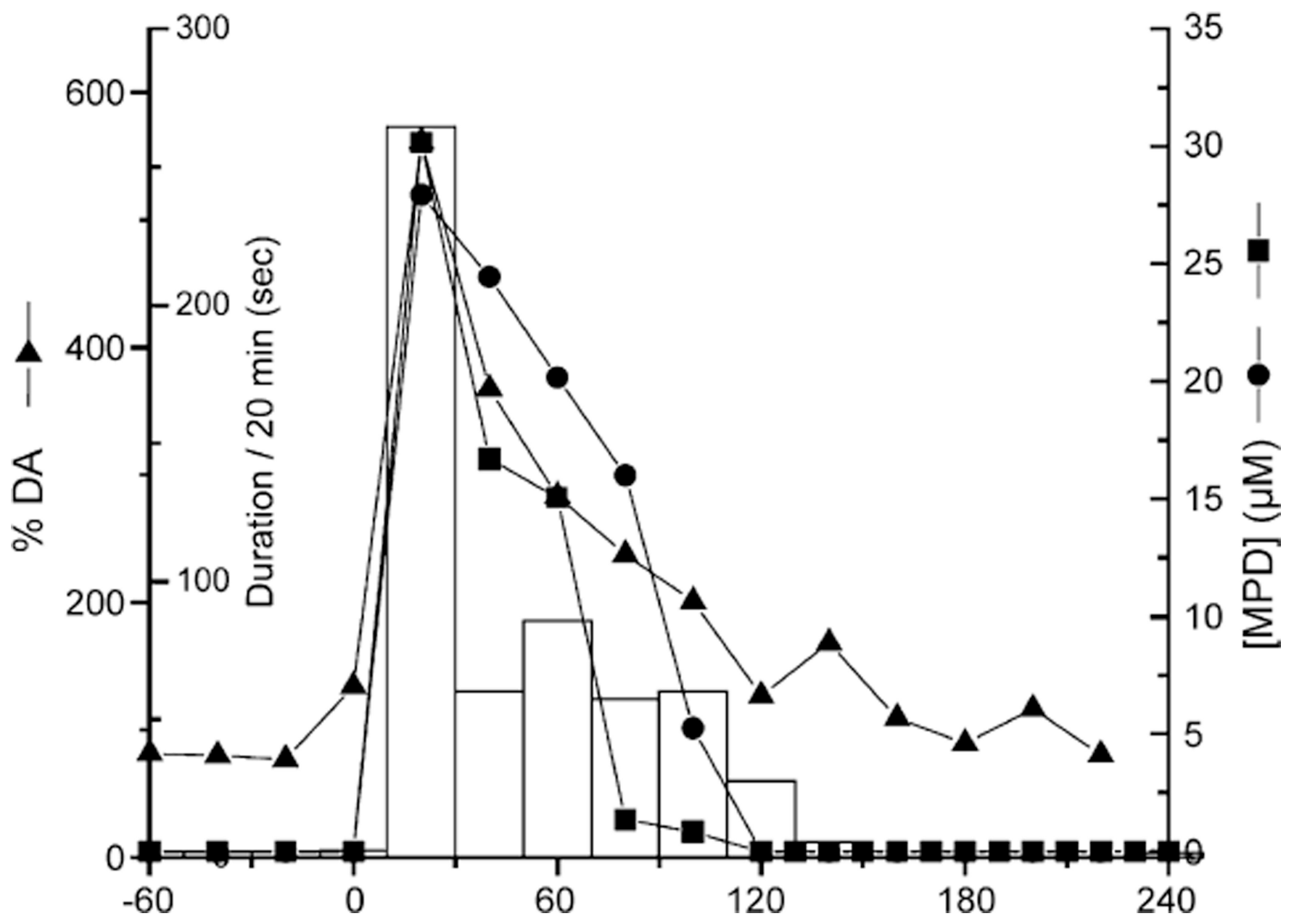

Fig. 3.

Simultaneous monitoring of dopamine and methylphenidate (MPD) from multiple probes. The filled squares represent MPD from jugular dialysate, the filled circles represent MPD from brain dialysate, and the filled triangles are \% dopamine with respect to basal. $X$-axis is the time from dosing in minutes. (From Huff and Davies, [28].) 


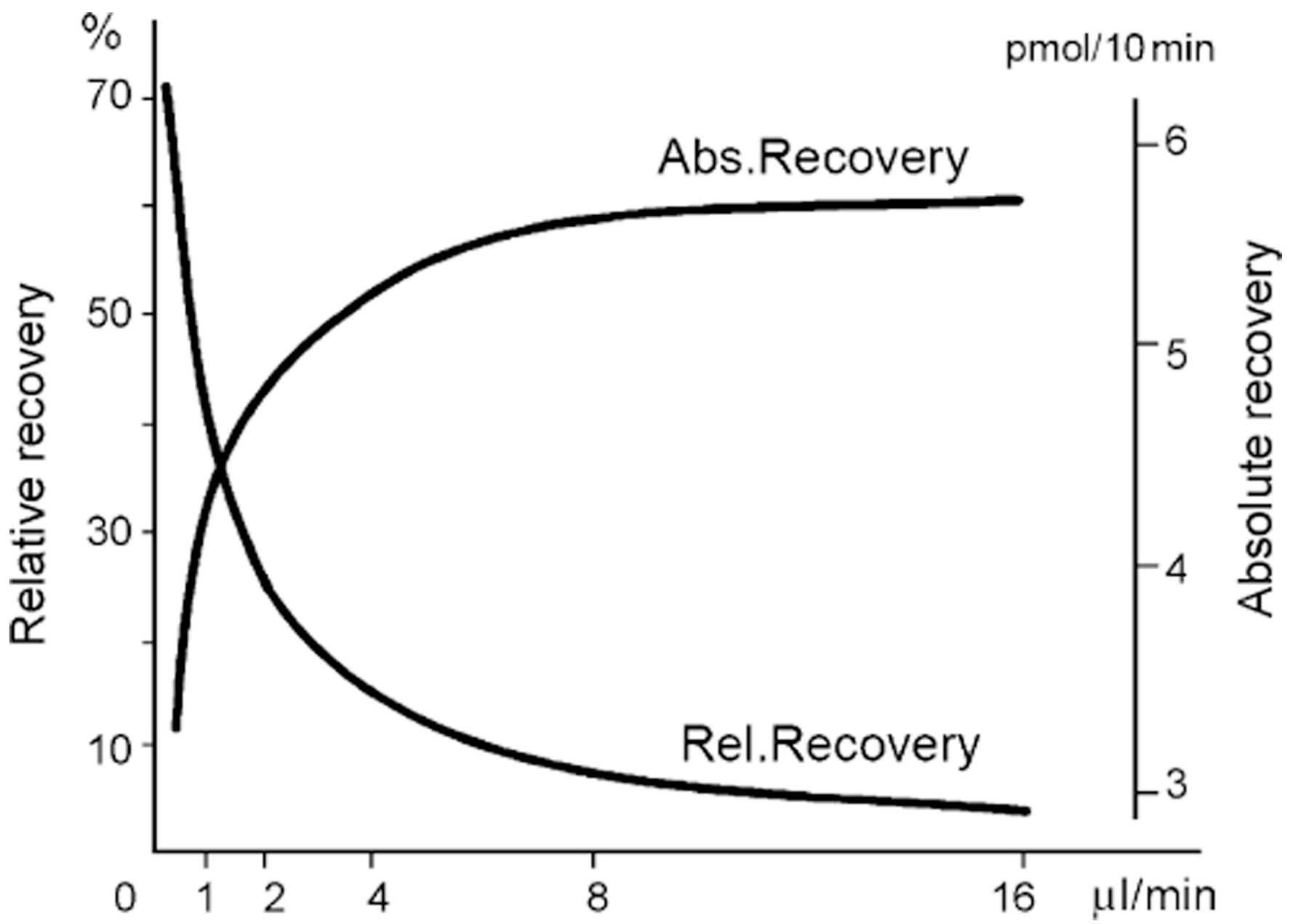

Fig. 4.

Relative and absolute recoveries of dopamine as a function of flow rate (from "Microdialysis-principles of recovery" by Agneta Eliasson, 1991). 


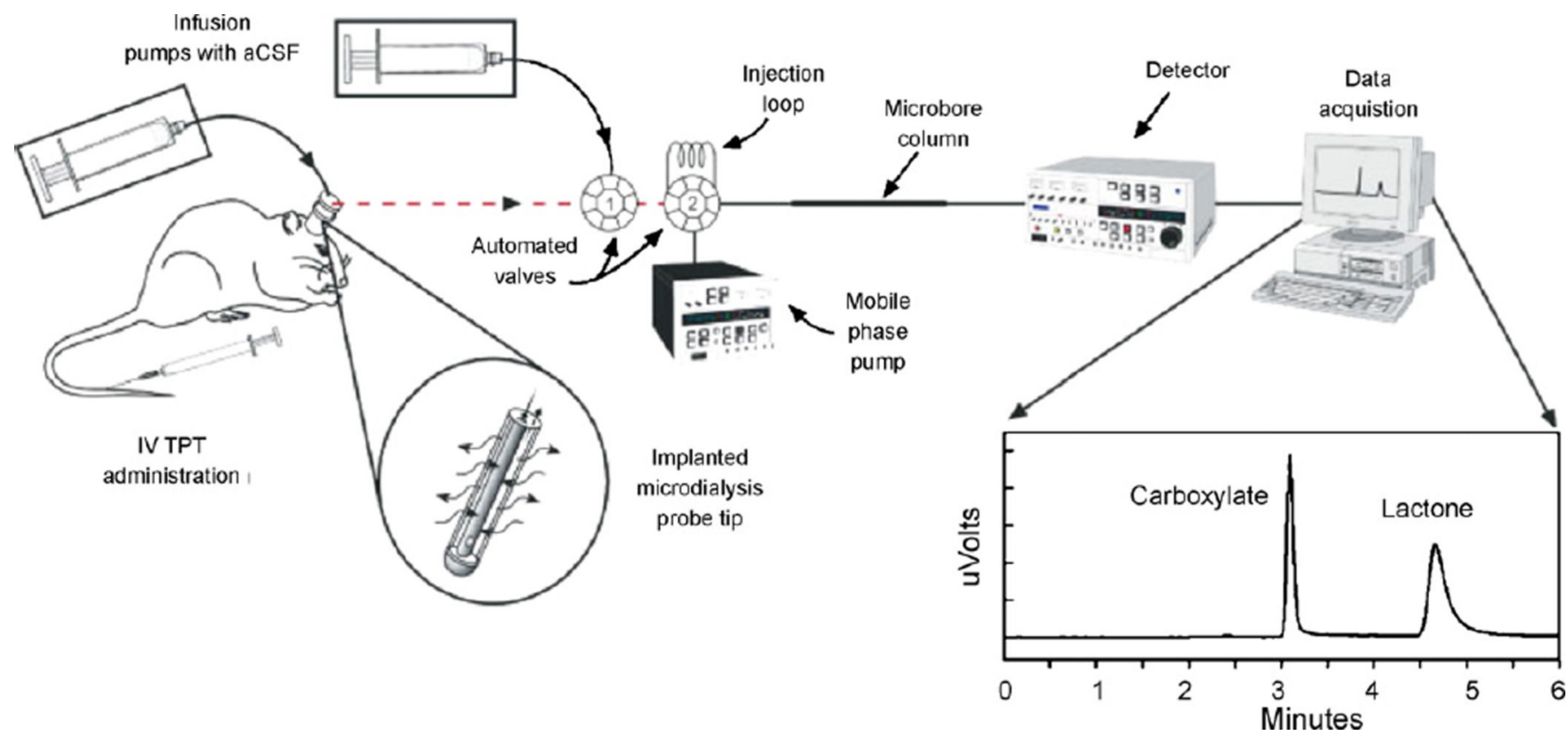

Fig. 5.

Setup of an online microdialysis-LC system (from Leggas et al. [97]). 

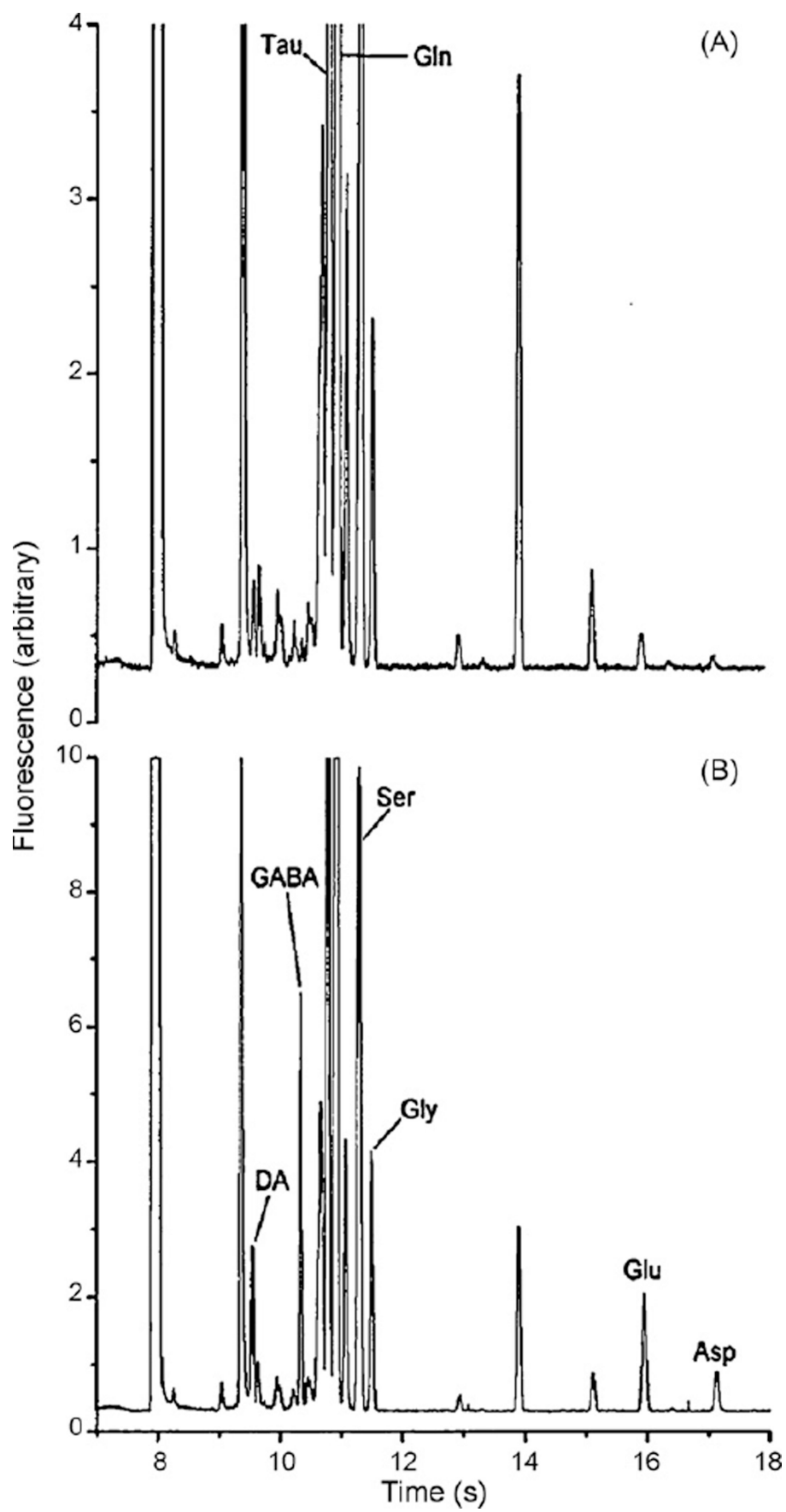

Fig. 6.

Change in concentration of amino acids following potassium ion stimulation. (A) Basal. (B) After $\mathrm{K}^{+}$stimulation. (Bowser and Kennedy [57].) 
(A)

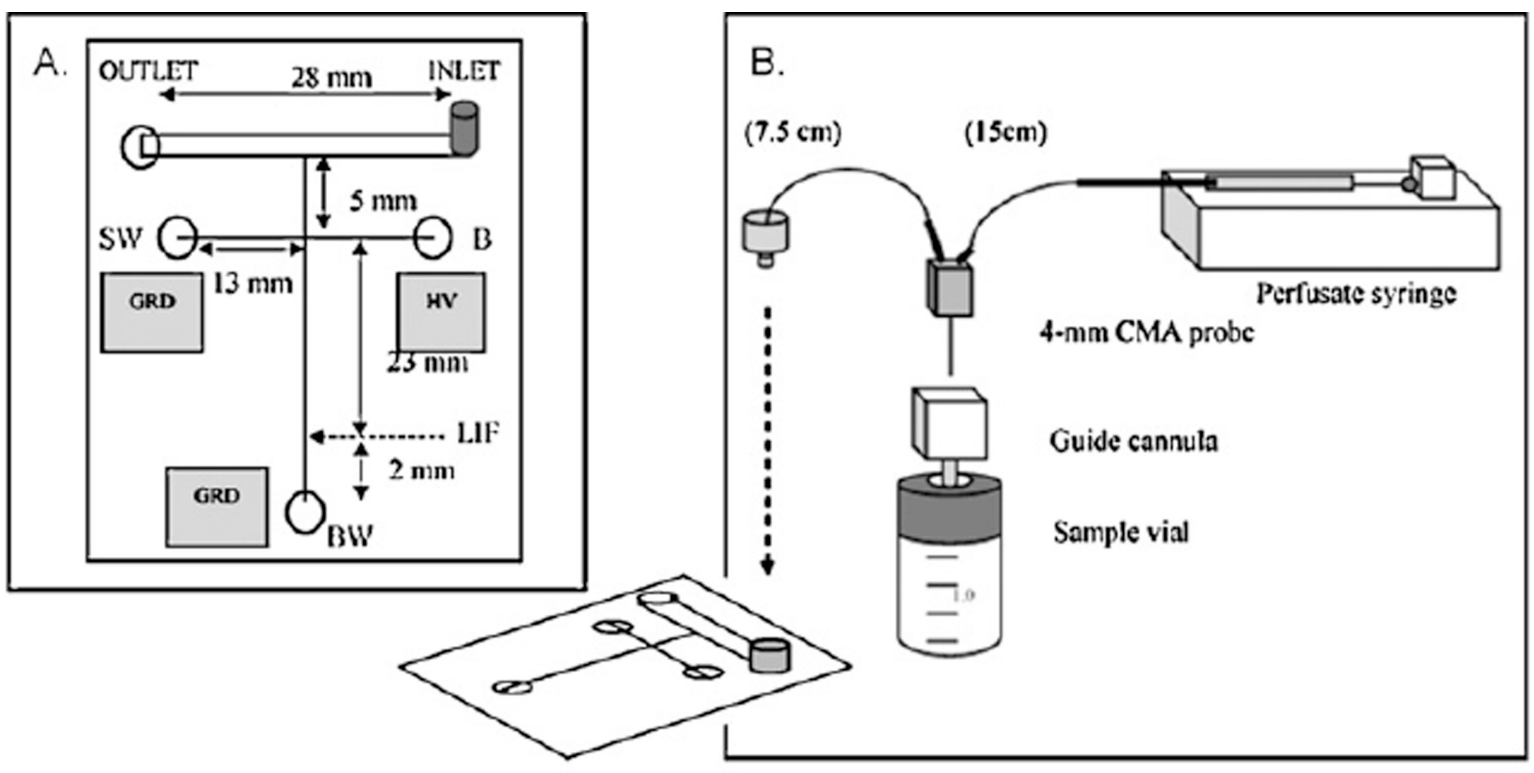

(B)

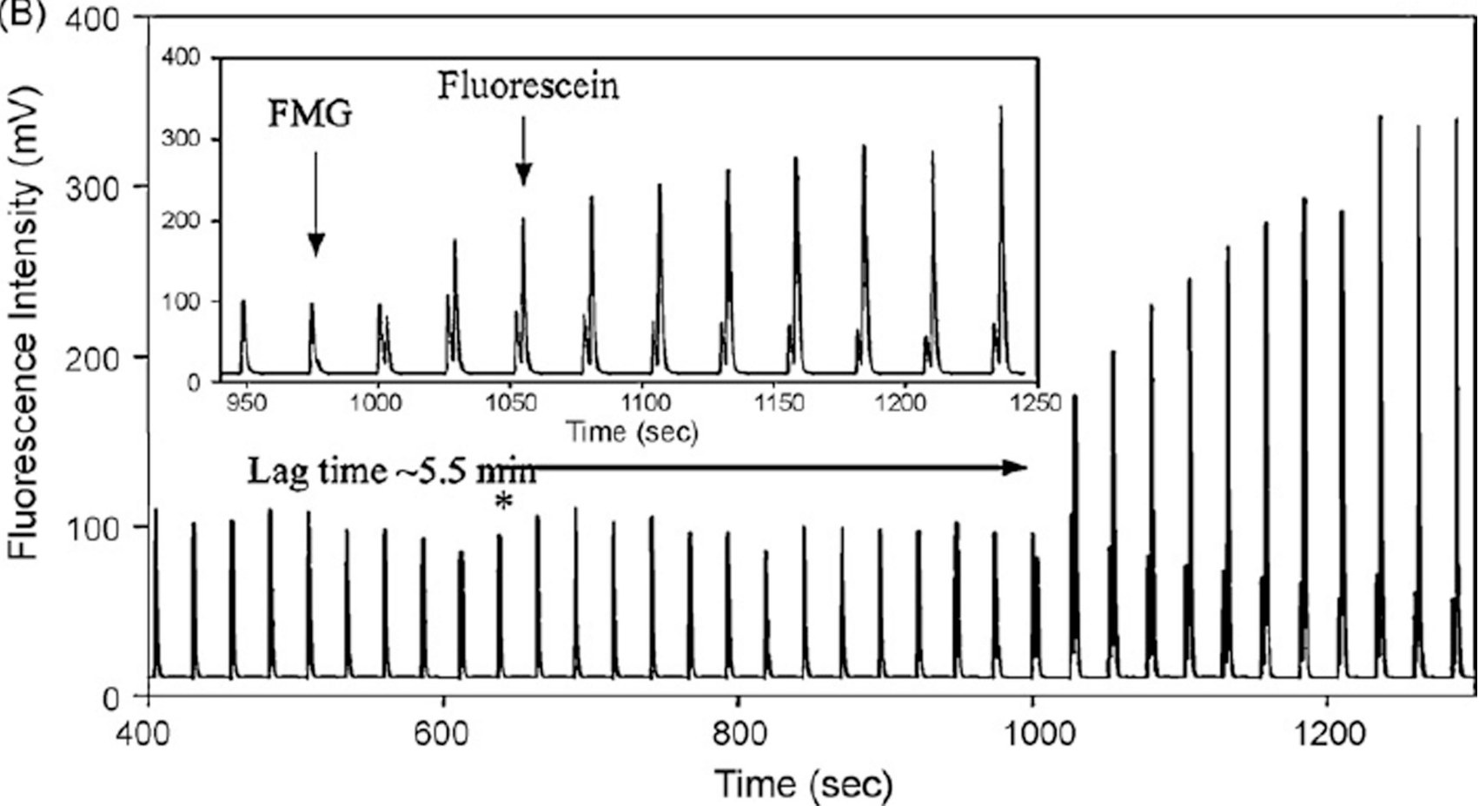

Fig. 7.

Online in vitro microdialysis microchip. (A) Chip design and setup. (B) In vitro enzyme assay of FMG (lag time 5.5min). (From Huynh et al. [62].) 


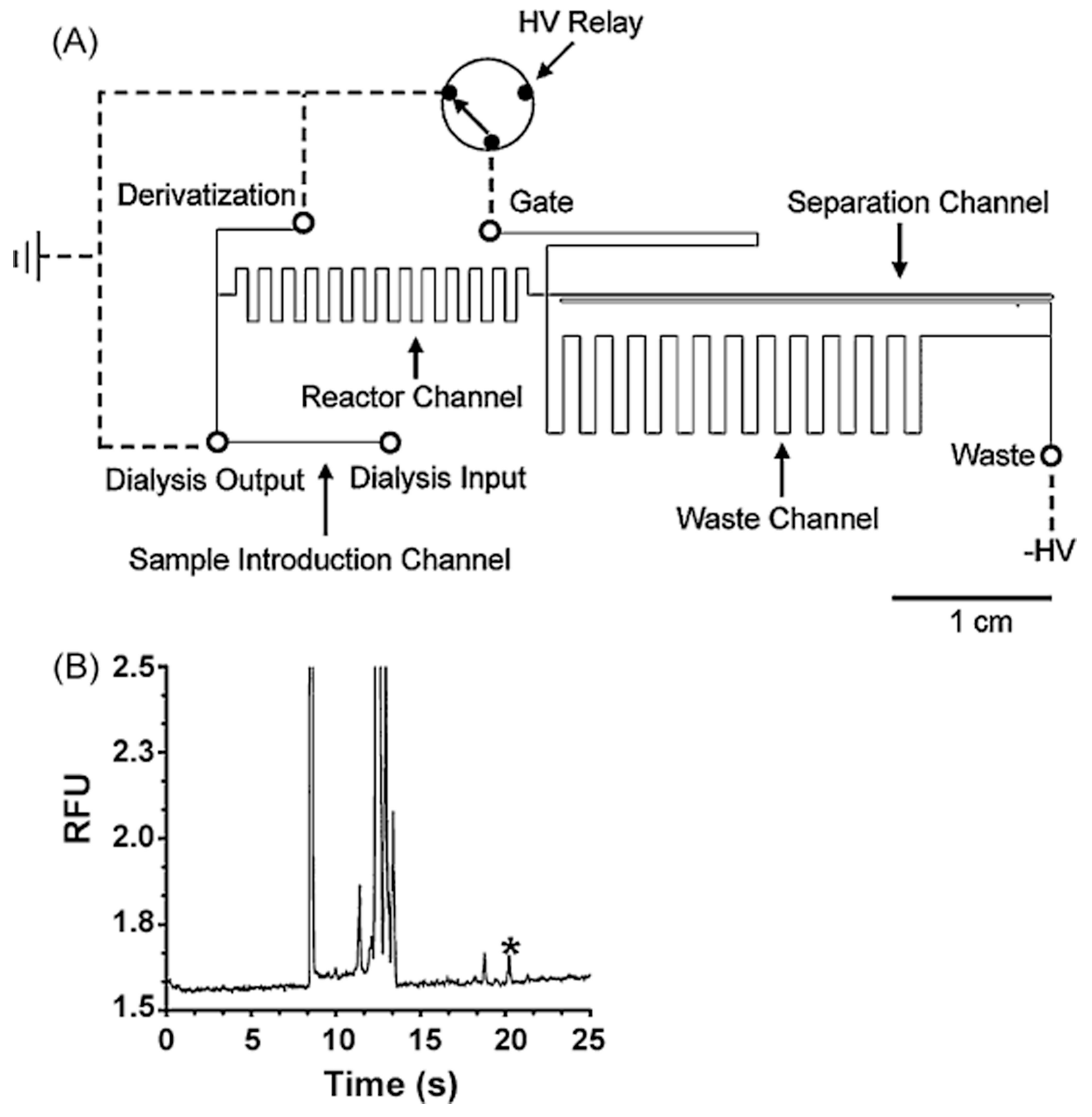

Fig. 8.

Online in vivo microdialysis microchip. (A) Chip design. (B) Microdialysis sample analysis (marked peak is glutamate). (From Sandlin et al. [64].) 
(A)

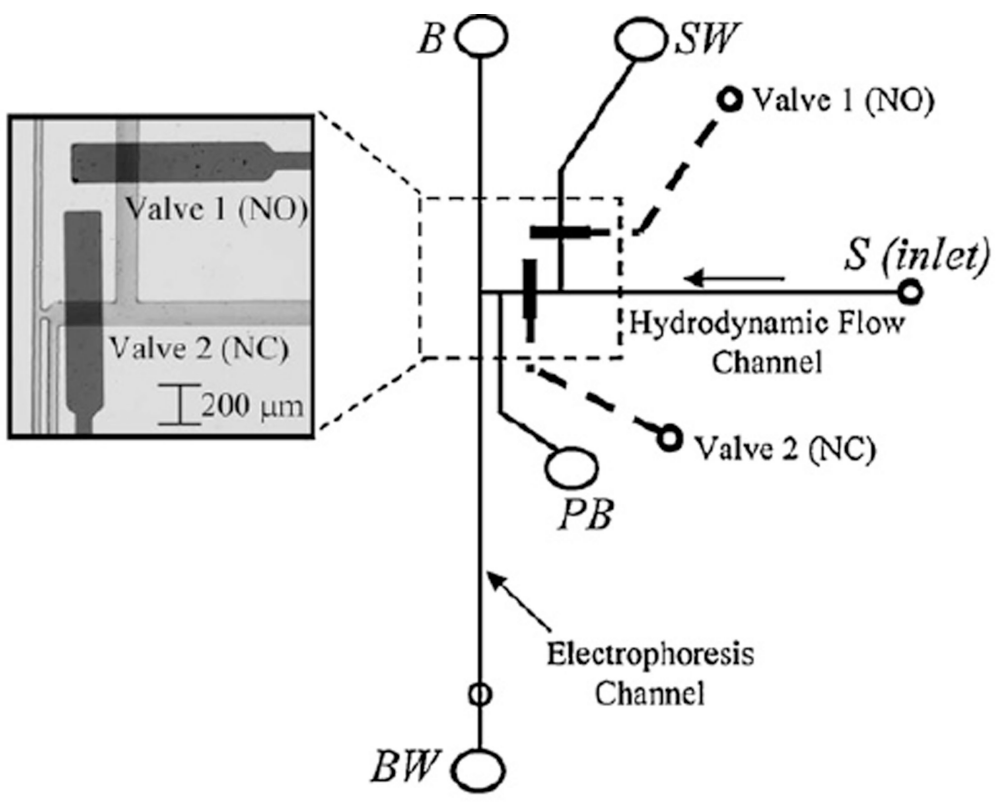

(B)

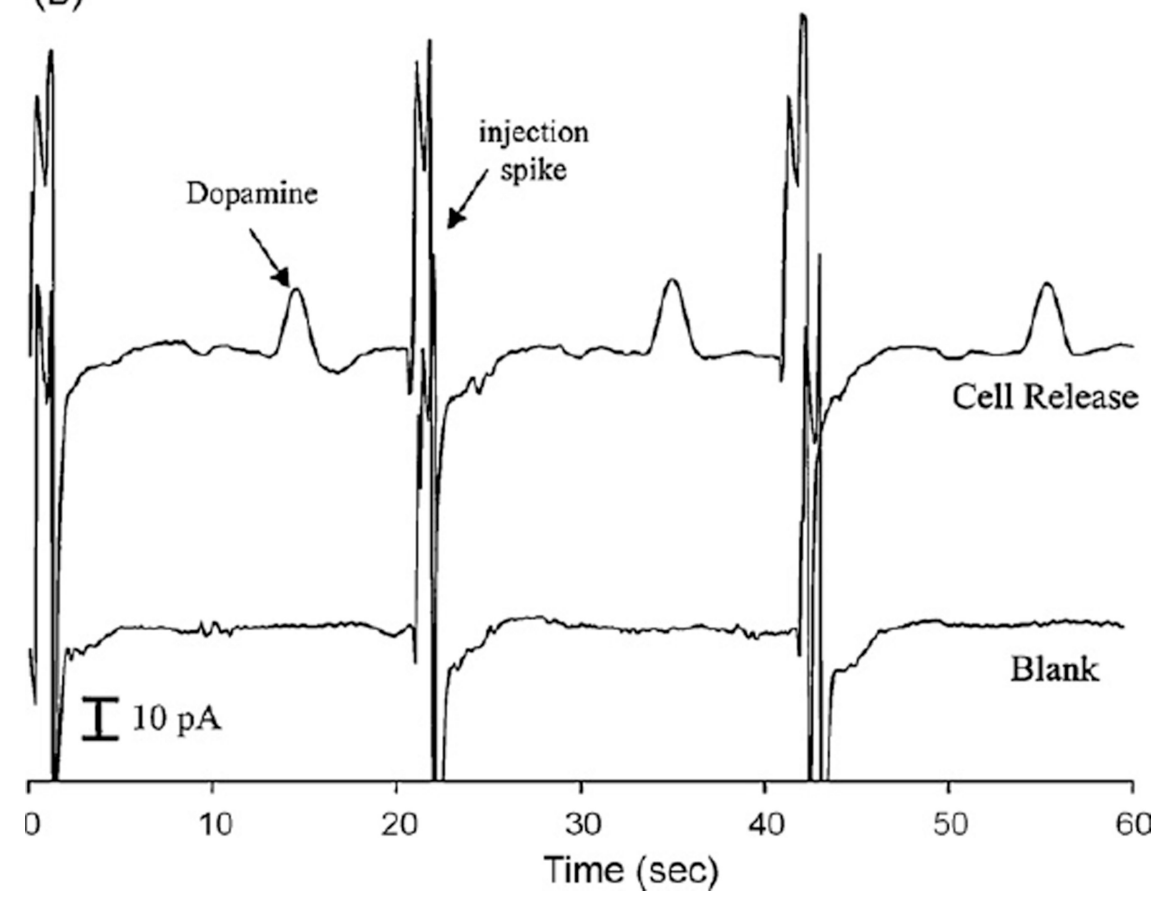

Fig. 9.

PDMS microchips with pneumatic valving. (A) Chip with 2 valves (1 and 2). (B) BW and $\mathrm{SW}$ are buffer, buffer waste and sample waste, respectively. NO and $\mathrm{NC}$ refer to valves that are "normally open" and "normally closed," respectively. (B) Online detection of dopamine from PC 12 cells. (From Mecker and Martin [41].) 
(A)

\section{Perfluorodecalin}

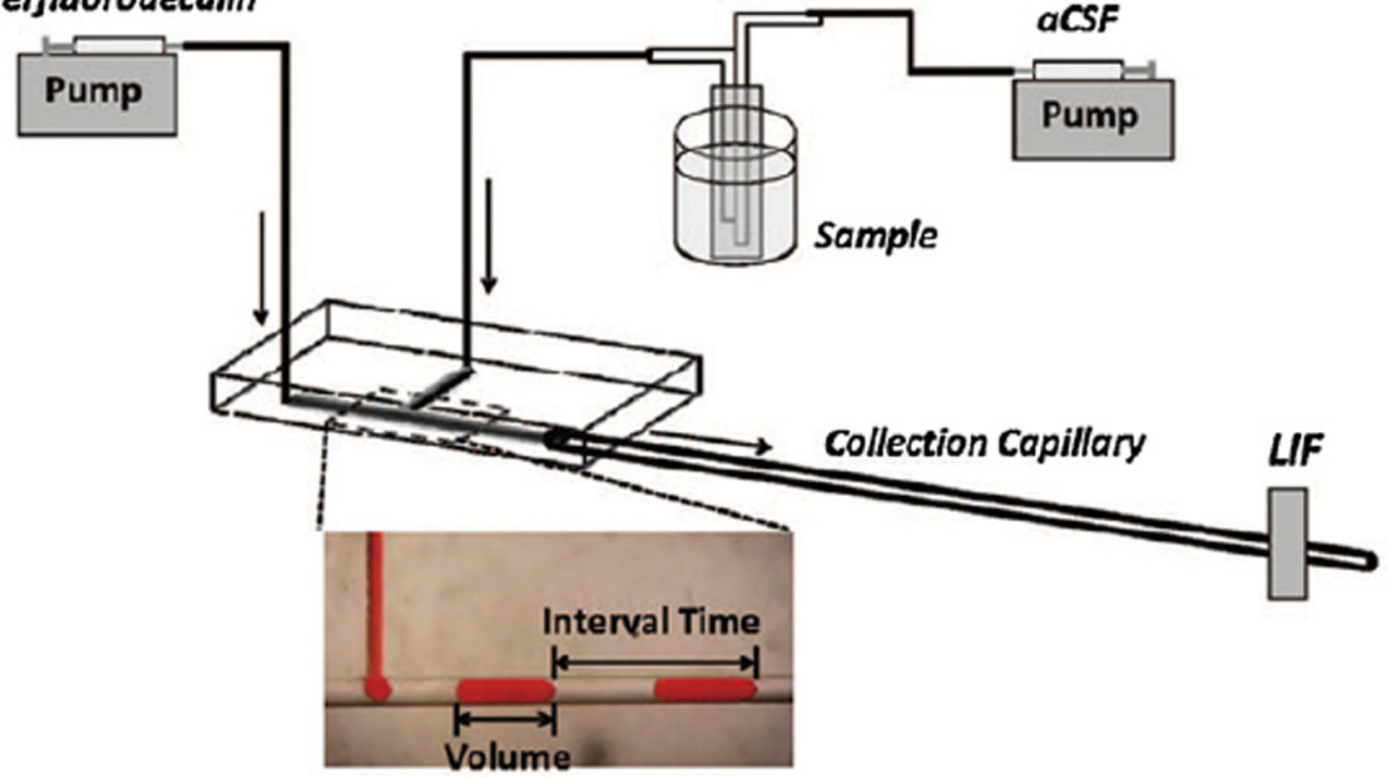

(B)

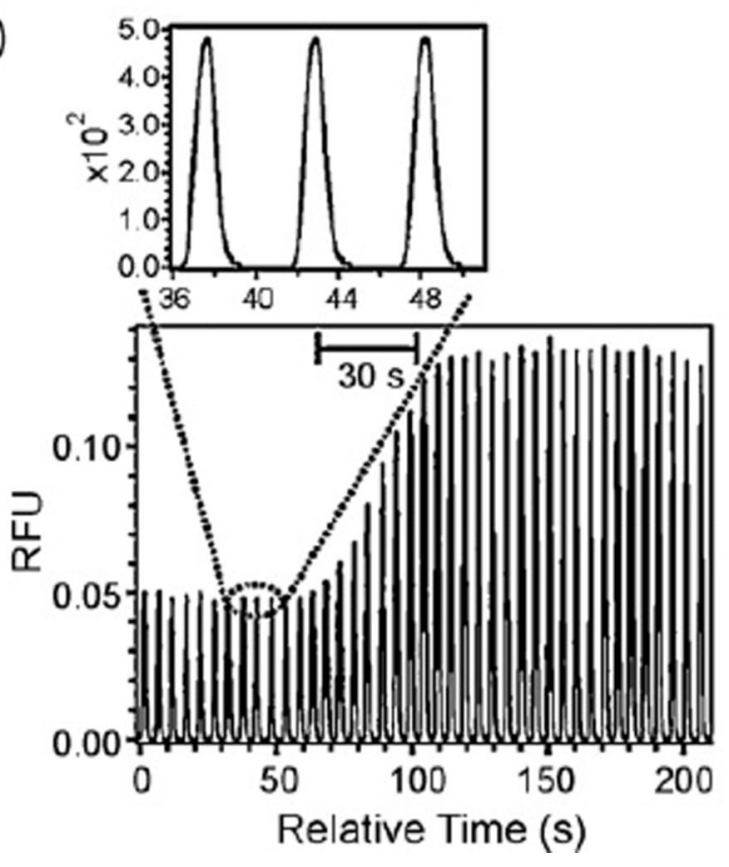

Fig. 10.

Segmented flow for flow-through analysis. (A) Setup. (B) LIF response for glucose after reaction with glucose oxadase (GOX)/horseradish peroxidase (HRP) and Amplex Red toproduce fluorescent Resorufin. The concentration of glucose was changed at the probe from 0.2 to $1 \mathrm{~mm}$. (From Wang et al. [67].) 


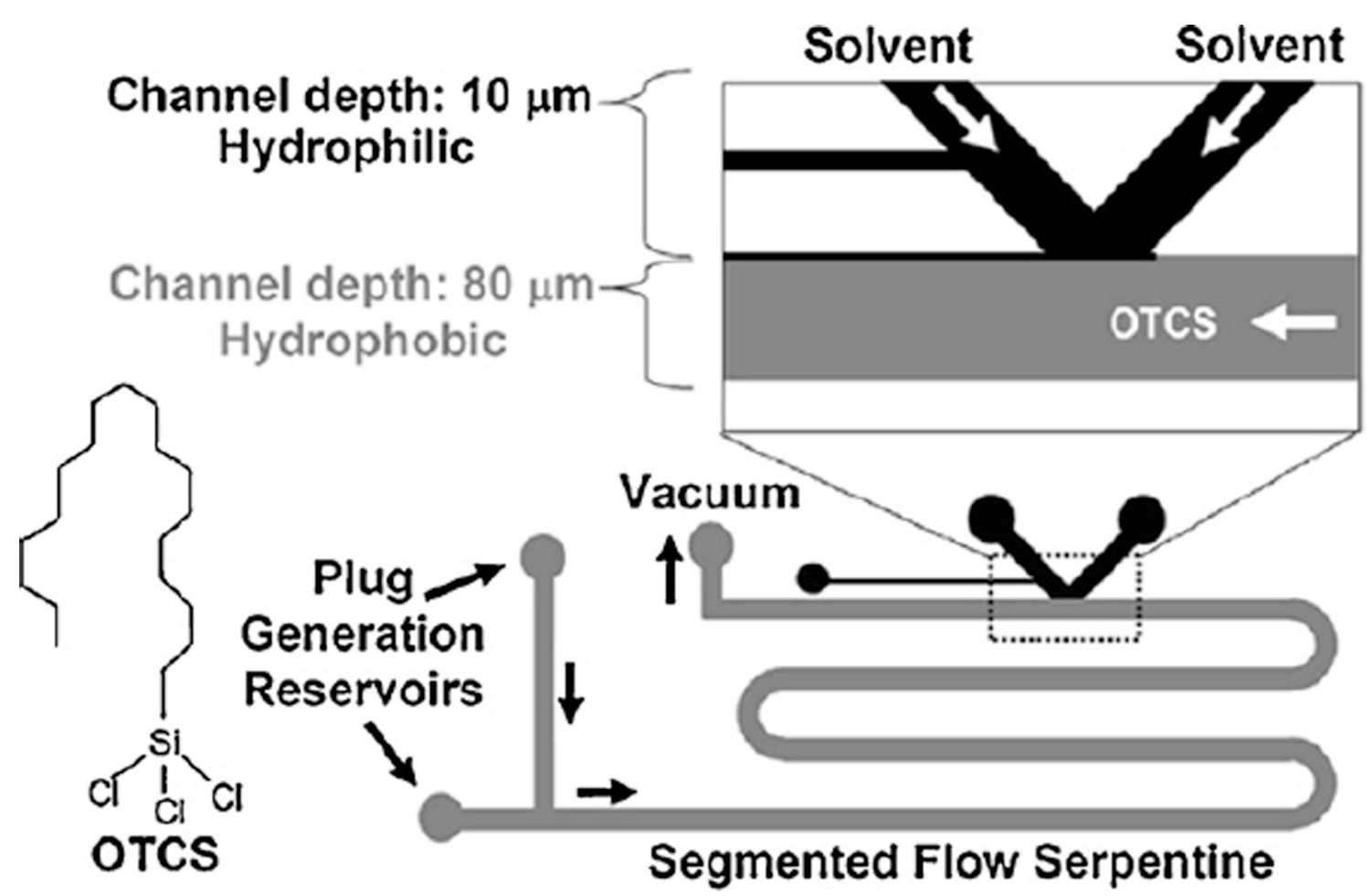

1 MM AA sample Blank solution
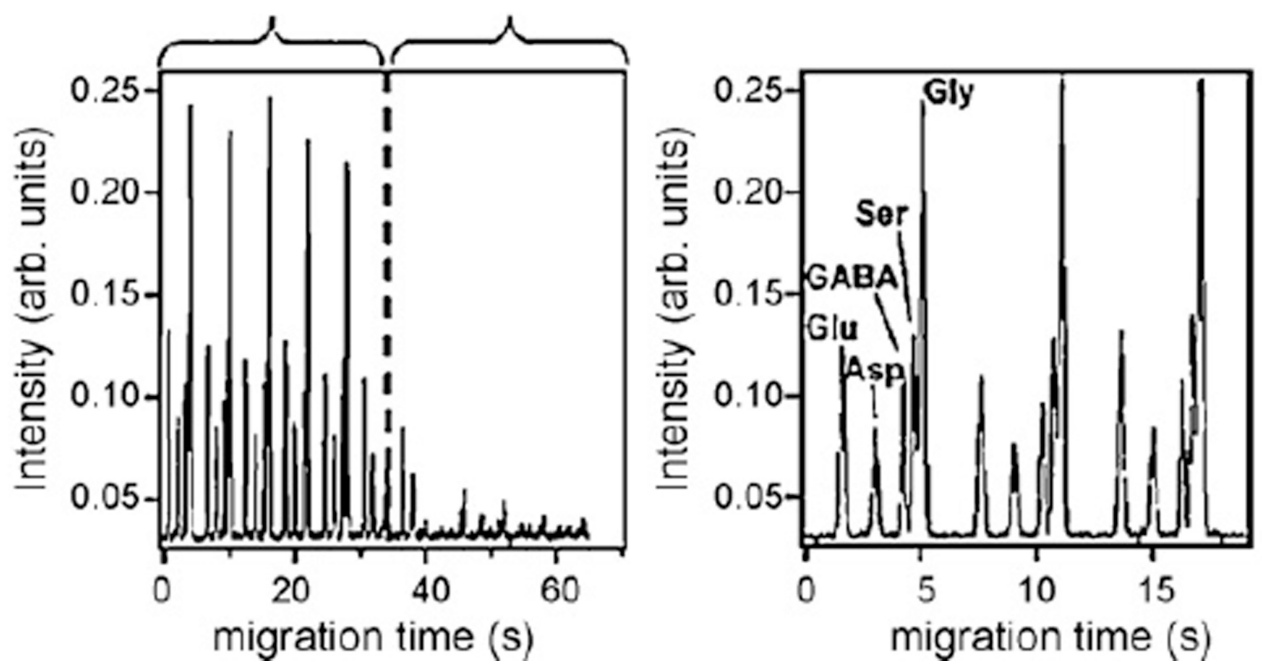

Fig. 11.

Glass microchip for segmented flow and electrophoretic separation. (A) Design. (B) Amino acid analysis after derivatization with NDA/CN. (From Roman et al. [68].) 
Table 1

Microdialysis-LC.

\begin{tabular}{|c|c|c|}
\hline Region of interest & Analyte(s) & Detection scheme \\
\hline Rat common bile duct & $\begin{array}{l}\text { Cefepime, moropenem, } \\
\text { diclofenac }\end{array}$ & UV [85-87] \\
\hline Rat jugular vein & $\begin{array}{l}\text { Cefsulodin, ceftriaxone, } \\
\text { cefmetazole, } \\
\text { cephaloridine } \\
\text { chloramphenicol, } \\
\text { glucuronide }\end{array}$ & UV [88-92] \\
\hline Rat liver & Glutathione & EC [93] \\
\hline Rat brain & Serotonin, trazodone & EC $[94,95]$ \\
\hline $\begin{array}{l}\text { Rat blood jugular vein } \\
\text { and brain striatum }\end{array}$ & Cephalexin & UV [96] \\
\hline $\begin{array}{l}\text { Rat brain lateral } \\
\text { ventricle }\end{array}$ & $\begin{array}{l}\text { Topotecan lactone, } \\
\text { carboxylate }\end{array}$ & FL [97] \\
\hline Rat brain striatum & $\begin{array}{l}\text { Monoamines and their } \\
\text { metabolites }\end{array}$ & EC [44] \\
\hline Rat urinary bladder & $\begin{array}{l}\text { Arsenite (AsIII), } \\
\text { arsenate (AsV), } \\
\text { monomethylarsonic } \\
\text { acid (MMA) and } \\
\text { dimethylarsinic acid } \\
\text { (DMA) }\end{array}$ & $\begin{array}{l}\text { Hydride generation } \\
\text { atomic absorption } \\
\text { spectrometry (HGAAG) } \\
{[98}\end{array}$ \\
\hline $\begin{array}{l}\text { Rat brain striatum and } \\
\text { heart ventricle }\end{array}$ & Ascorbic acid & $\mathrm{EC}[36]$ \\
\hline Rat brain striatum & Acetyl choline & EC [36] \\
\hline Rat brain & Rhodamine 123 & FL [99] \\
\hline Rat bile duct & Camptothecin & FL [100] \\
\hline Rat brain striatum & Serotonin & FL [47] \\
\hline Rat brain and plasma & EAB 515 & FL [101] \\
\hline Rat brain & Malondialdehyde & FL [102] \\
\hline Rat brain striatum & Acetyl choline & MS [46] \\
\hline Rat jugular vein & Melatonin & MS [48] \\
\hline
\end{tabular}


Table 2

Microdialysis-CE.

\begin{tabular}{|lll|}
\hline Region of interest & Analyte(s) & $\begin{array}{l}\text { Detection } \\
\text { scheme }\end{array}$ \\
\hline Rat brain striatum & Glucose, lactate & EC [84] \\
Rat brain striatum & Dopamine & FL [61] \\
Rat brain coronal slice & $\begin{array}{l}\text { Serine, taurine, } \\
\text { glutamate GABA }\end{array}$ & FL [103] \\
Rat brain striatum & D-serine & FL [104] \\
Larval tiger salamander retina & $\begin{array}{l}\text { Amino acid } \\
\text { neurotransmitters }\end{array}$ & FL [105] \\
Larval tiger salamander retina & D,L-serine & FL [106] \\
Rat brain striatum & $\begin{array}{l}\text { Amino acid } \\
\text { neurotransmitters }\end{array}$ & FL [57] \\
Rat dermis & Nicotine & EC [54] \\
Rat brain striatum & $\begin{array}{l}\text { O-phospho- } \\
\text { ethanolamine, } \\
\text { excitatory amino } \\
\text { acid }\end{array}$ & FL [60] \\
Rat brain striatum & $\begin{array}{l}\text { Glutamate and } \\
\text { aspartate }\end{array}$ & FL [24] \\
Rat caudate nucleus & $\begin{array}{l}\text { Glutathione and } \\
\text { cysteine }\end{array}$ & FL [59] \\
Rat caudate nucleus & Primary amines & FL [56] \\
Rat caudate nucleus & Ascorbate & UV [58] \\
Rat brain hippocampus & $\begin{array}{l}\text { Glutamate and } \\
\text { aspartate }\end{array}$ & FL [53] \\
Rat vein (opposite to jugular vein) & $\begin{array}{l}\text { Antineoplastic } \\
\text { agent }\end{array}$ & FL [52] \\
\hline
\end{tabular}


Table 3

Microdialysis-microchip electrophoresis.

\begin{tabular}{|lll|}
\hline Region of interest & Analyte(s) & Detection scheme \\
\hline In vitro enzyme assay & $\begin{array}{l}\text { Conversion of FMG to } \\
\text { fluorescein by } \beta \text {-gal }\end{array}$ & LIF [62] \\
Rat brain striatum & Glutamate & LIF [64] \\
In vitro analysis & $\begin{array}{l}\text { Gly-Pro, Leu-Enk, } \\
\text { glutamate, aspartate, } \\
\text { fluorescein, } \\
\text { dichlorofluorescein, GABA, } \\
\text { serine, glycine }\end{array}$ & LIF [63,66,68] \\
In vitro analysis (PC12 cell) & Dopamine & EC [41] \\
\hline
\end{tabular}


Table 4

Microdialysis-biosensor.

\begin{tabular}{|lll|}
\hline Region of interest & Analyte(s) & Detection scheme \\
\hline Rat brain striatum & Glucose, glutamate, lactate & EC [74,77,82,84] \\
Rat subcutaneous tissue & Glucose, lactate & EC [75] \\
Rat cortex & Glucose, lactate & EC [78] \\
Frontal lobe of rat brain & $\begin{array}{l}\text { Glucose, L-lactate, } \\
\text { pyruvate, acetyl choline, } \\
\text { dopamine }\end{array}$ & EC [79,80] \\
Rat jugular & Glucose & Chemiluminescence [83] \\
\hline
\end{tabular}

